\title{
Influence of conical projectile diameter on perpendicular impact of thin steel plate
}

\author{
A. Rusinek ${ }^{\mathrm{a}}$, J.A. Rodríguez-Martínez ${ }^{\mathrm{b}}$, A. Arias ${ }^{\mathrm{b}, *}$, \\ J.R. Klepaczko ${ }^{a}$, J. López-Puente ${ }^{\mathrm{b}}$ \\ ${ }^{a}$ Laboratory of Physic and Mechanic of Materials, UMR CNRS 75 54, University Paul Verlaine of Metz, Ile du Saulcy, \\ 57045 Metz Cedex, France \\ ${ }^{\mathrm{b}}$ Department of Continuum Mechanics and Structural Analysis, University Carlos III of Madrid, \\ Avda. de la Universidad 30, 28911 Leganés, Madrid, Spain
}

\begin{abstract}
A numerical study of conical projectiles for perpendicular impact on a thin steel plate is reported. The target material considered, Weldox $460 \mathrm{E}$ steel, is frequently used for this kind of application and several results of experiments are avail able in the international literature to verify numerical simulations. The Johnson Cook constitutive relation coupled with the Johnson Cook failure criterion have been applied to analyse penetration of the target and also the failure process. The analysis has been focussed on the influence of the projectile diameter on the perforation process, assuming the same projectile mass. The aim was to preserve the same initial kinetic energy and identical nose angle. The goal is to estimate the ballistic limit, the residual velocity, the plastic work, and the temperature levels produced during the penetration process. The analysis has shown a linear increase of the ballistic limit with the projectile diameter.
\end{abstract}

Keywords: Dynamic behaviour; Ductile failure; Numerical simulation; Perforation

\section{Introduction}

High-velocity impact behaviour of metallic plates by a rigid body has been studied during several last years, mainly due to large interest for ballistic applications [1 4]. Additionally, this problem is also important for industrial processes, as in fast cutting by punch-plate to reduce production time. Thus, several studies on this subject are available in the literature, and comprehensive reviews can be found in the works of Backman and Goldsmith [5], Corbett et al. [6] and Zukas et al. [7,8], dealing with several features of the phenomena involved.

For this kind of configuration like impact of projectile on a plate, typically metal metal arrangement, the projectile-nose shape determines the failure mode and strongly affects the amount of energy absorbed by the plate $\left[\begin{array}{ll}9 & 13\end{array}\right]$. Particularly important efforts have been made to estimate the lowest impact velocity leading to

\footnotetext{
* Corresponding author. Tel.: +34 91624 9161; fax: +34 916249430.

E mail address: angelarias@uc3m.es (A. Arias).
} 


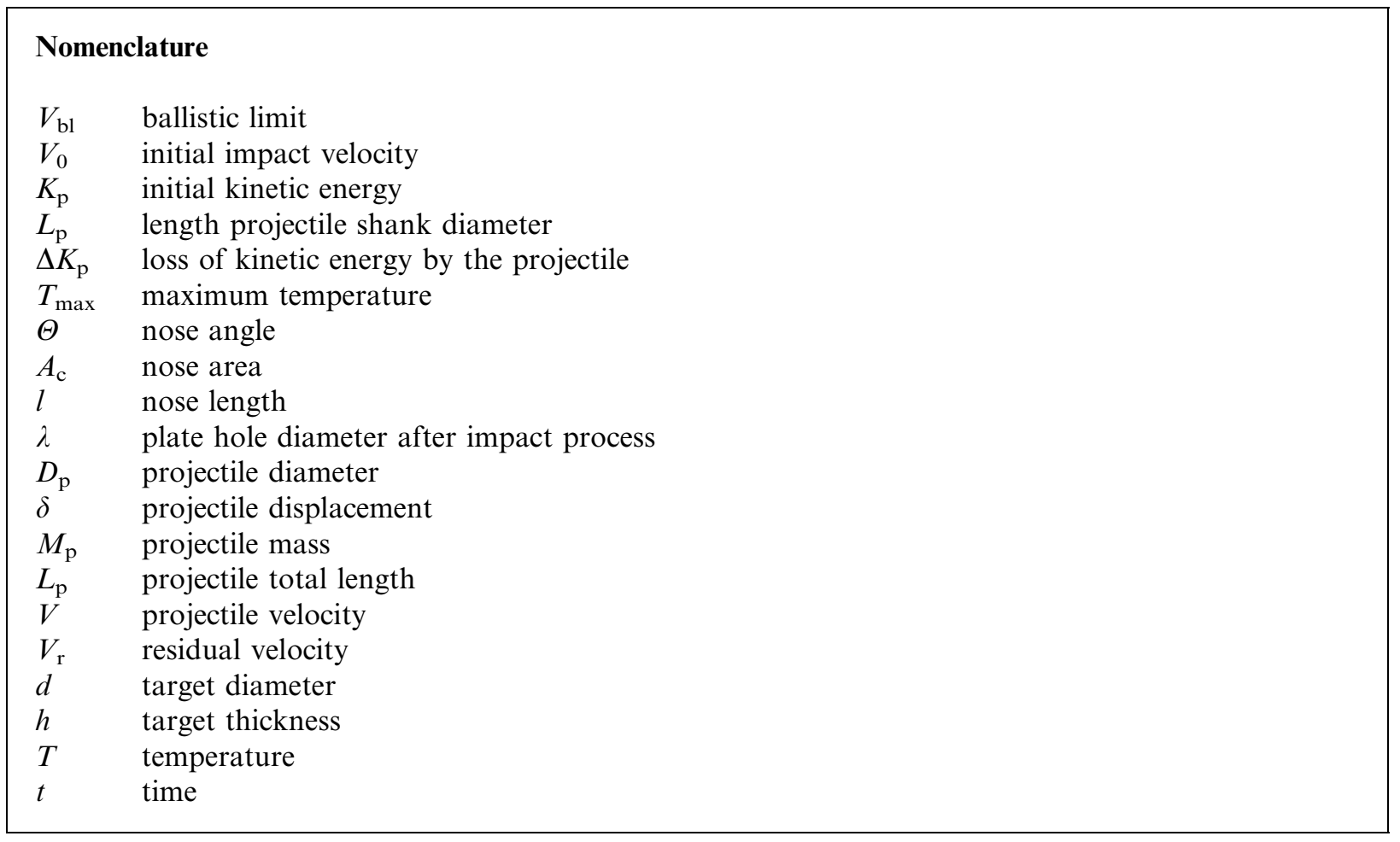

the complete perforation of the target corresponding to different projectile-plate configurations. This value of impact velocity is known as ballistic limit [8].

Thus, it is known that application of cylindrical projectiles having flat faces causes the perforation via adiabatic shear-band propagation, inducing a plug ejection as the final stage $[9,10,13$ 15], and reducing the value of ballistic limit. On the contrary, a complete perforation of plates appears by ductile hole enlargement and petalling. This occurs when ogival, conical, or hemispherical projectiles are used [13,16 20].

During perforation process by rigid conical projectiles, the target material is tear away by projectile movement. The nose surface is in frictional contact with the target, inducing an additional energy dissipation, which can affect the results obtained, for example [13]. However, bending effect and compressive stresses predominate during penetration. This mode of penetration produces a larger plastic flow zone affected by impact and the plastic work is higher in comparison with cylindrical projectile [13]. Such kind of penetration process appears to be more efficient for perforating the target at high initial impact velocity but it results in higher values for the ballistic limit, $[9,10,13]$.

The penetration process of metals depends substantially on the local strain hardening rate, $\mathrm{d} \sigma / \mathrm{d} \varepsilon^{\mathrm{p}}$, strain rate, $\dot{\varepsilon}^{\mathrm{p}}$ and temperature, $T$. Therefore, in order to analyse a complete behaviour of the target, it requires a constitutive relation which takes these variables into account. Several constitutive relations can be found in the international literature, which are adequate to approximate visco-plastic behaviour of steels under dynamic and complex state of stress [21 28]. A more general analysis concerning this topic can be found in the works of Liang and Khan [29] and Rusinek et al. [30]. In the present work the Johnson Cook constitutive equation $\sigma\left(\varepsilon^{\mathrm{p}}, \dot{\varepsilon}^{\mathrm{p}}, T\right)$ [25], which is widely used to calculate dynamic events, for example [11 13,31], has been used to analyse the target behaviour. In addition, the Johnson Cook failure criterion, $\varepsilon_{\mathrm{f}}^{\mathrm{p}}\left(\dot{\varepsilon}^{\mathrm{p}}, T\right)$ [32], has been coupled with the Johnson Cook constitutive relation for a complete description of the problem. However, high-velocity impact on plates is complex in terms of numerical approach. Frequently, numerical-convergence problems arise due to excessive element distortion, especially when conical projectiles are used [10,13], preventing a complete time calculation. The convergence problem can be reduced by an adaptive mesh algorithm, as reported elsewhere [10 13].

In this work the FE commercial code, ABAQUS/Explicit has been used to simulate perpendicular impact with different conical projectile diameters on a Weldox $460 \mathrm{E}$ steel plate. The conical nose shape of the 
projectiles is commonly used in ballistic applications, Fig. 1a. This figure illustrates a 0.5 NATO projectile with a mass of $25 \mathrm{~g}$ steel core, and ratio length/diameter, $L_{\mathrm{p}} / D_{\mathrm{p}} \quad 4.3$. The numerical model that was introduced in the FE Code has been validated using experimental data reported by Borvik et al. [9]. The experimental arrangement is shown in Fig. 1b. The simulations have been carried out for a wide range of impact velocity: $265 \mathrm{~m} / \mathrm{s} \leqslant V_{0} \leqslant 600 \mathrm{~m} / \mathrm{s}$. The calibre of the projectile has been changed while keeping a constant projectile mass, $M_{\mathrm{p}}$ and nose angle $\Theta$. It was then possible to evaluate the influence of the projectile diameter, and therefore the nose area, on the ballistic limit, the residual velocity, and the plastic work. A linear relationship between the ballistic limit and the projectile diameter is proposed in a general form: $V_{\mathrm{bl}} \propto D_{\mathrm{p}}$.

The analysis performed leads to several conclusions on mechanical behaviour of the metallic plates loaded by a normal impact and materials studied in dynamic applications $[9,10,13,33,34]$.

\section{Target material}

Weldox $460 \mathrm{E}$ steel is a thermo-mechanically rolled ferritic structural steel offering high strength combined with a high ductility $[9,14,33,34]$. The yield stress is close to $\sigma_{y} \approx 500 \mathrm{MPa}$ with the failure stress of $\sigma_{\text {failure }} \geqslant 1 \mathrm{GPa}$. Such behaviour was modelled using the Johnson Cook constitutive relation which takes into account strain-rate sensitivity, strain hardening, and thermal softening. This model is frequently used to simulate dynamic processes such as perforation. The equivalent Huber Misses stress, $\sigma$, is defined as follows:

$$
\begin{aligned}
& \sigma\left(\varepsilon^{\mathrm{p}}, \dot{\varepsilon}^{\mathrm{p}}, T\right)=\left[C_{1}+C_{2}\left(\varepsilon^{\mathrm{p}}\right)^{n}\right] \cdot\left[1+C_{3} \ln \left(\frac{\dot{\varepsilon}^{\mathrm{p}}}{\dot{\varepsilon}_{0}}\right)\right] \cdot\left[1-T^{* m}\right] \\
& T^{*}=\frac{\left(T-T_{0}\right)}{\left(T_{\mathrm{m}}-T_{0}\right)}
\end{aligned}
$$

where $C_{1}$ is the quasi-static yield stress, $C_{2}$ is a hardening constant, $n$ is the hardening exponent, $C_{3}$ is the strain-rate sensitivity, and $m$ is the temperature sensitivity parameter; $\dot{\varepsilon}_{0}$ is the reference strain rate and $T^{*} \quad\left(T-T_{0}\right) /\left(T_{\mathrm{m}}-T_{0}\right)$ is the homologous temperature, where $T$ is the current temperature, $T_{0}$ is the room temperature and $T_{\mathrm{m}}$ is the melting temperature. These constants are reported in Table $1[13,14,33]$.

In addition, this constitutive relation is coupled with the heat equation, Eq. (3), it allows for taking into account the temperature increase $\Delta T$ during plastic deformation $\varepsilon_{\mathrm{p}}$ under adiabatic conditions. The temperature increase induces a thermal softening of the material leading to plastic instability followed by a complete failure $[20,30,35]$. A typical process of plastic instability appearing during perforation at high impact velocity is petalling. This process is commonly observed when hemispherical, ogival or conical projectiles strike thin plates $[13,1620]$. Therefore the adiabatic temperature increase must be introduced during dynamic processes
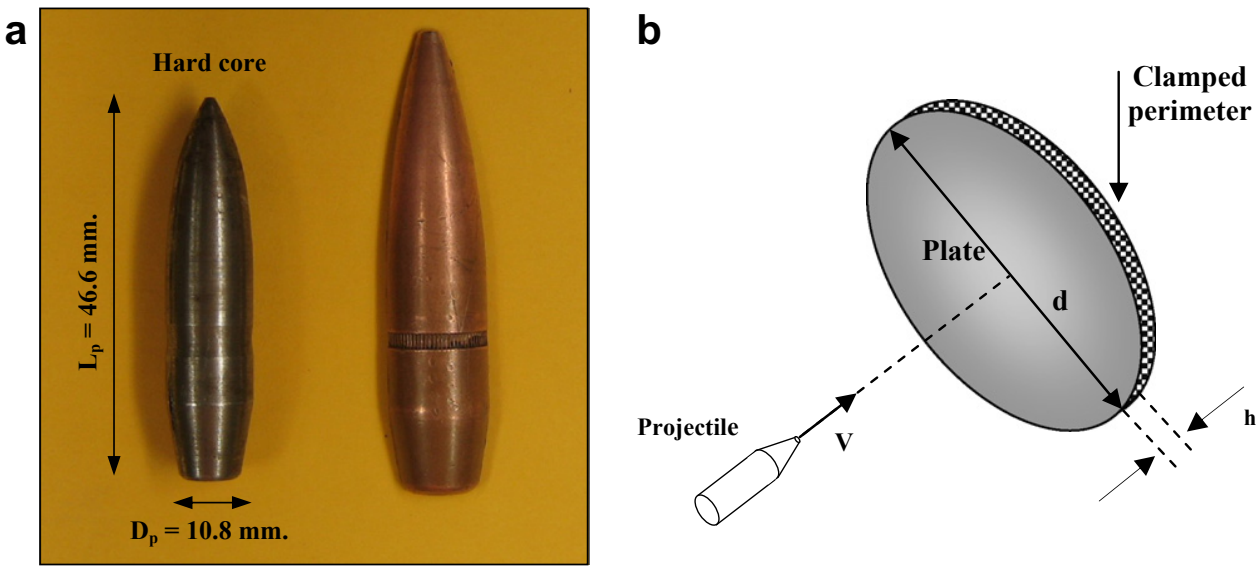

Fig. 1. (a) Projectile as a base in ballistic application, 0.5 NATO, (b) experimental arrangement and definition of boundary conditions [9]. 
Table 1

Constants used to define the thermoviscoplastic behaviour of Weldox 460 E steel $[13,14,33]$

\begin{tabular}{|c|c|c|c|c|c|}
\hline \multicolumn{6}{|l|}{ Elasticity } \\
\hline$E(\mathrm{GPa})$ & $v()$ & & & & \\
\hline 200 & 0.33 & & & & \\
\hline \multicolumn{6}{|c|}{ Thermoviscoplastic behaviour } \\
\hline$C_{1}(\mathrm{MPa})$ & $C_{2}(\mathrm{MPa})$ & $n()$ & $\dot{\varepsilon}_{0}\left(\mathrm{~s}^{1}\right)$ & $C_{3}(\quad)$ & $m(\quad)$ \\
\hline 490 & 807 & 0.73 & $5 \times 10^{4}$ & 0.012 & 0.94 \\
\hline \multicolumn{6}{|c|}{ Other physical constants } \\
\hline$\rho\left(\mathrm{kg} / \mathrm{m}^{3}\right)$ & $\beta()$ & $\rho(\mathrm{J} / \mathrm{kg} \mathrm{K})$ & $T_{\mathrm{m}}(\mathrm{K})$ & & \\
\hline 7850 & 0.9 & 452 & 1800 & & \\
\hline
\end{tabular}

such as perforation. The temperature increase induces thermal softening of the material deformed at high strain rates, Eq. (3). The adiabatic increase of temperature is given by

$$
\Delta T\left(\varepsilon^{\mathrm{p}}, \dot{\varepsilon}^{\mathrm{p}}, T_{0}\right)=\frac{\beta}{\rho C_{\mathrm{p}}} \int_{\varepsilon_{e}}^{\varepsilon^{\mathrm{p}}} \sigma\left(\varepsilon^{\mathrm{p}}, \dot{\varepsilon}^{\mathrm{p}}, T\right) \mathrm{d} \varepsilon^{\mathrm{p}}
$$

where $\beta$ is the Taylor Quinney coefficient, which defines the part of the plastic work converted into heat. Generally, the value of $\beta$ for steel is assumed constant, $\beta \quad 0.9$ [36], $\rho$ is the density of the material, and $C_{\mathrm{p}}$ is the specific heat at constant pressure.

The temperature and strain-rate sensitivity of Weldox 460 E steel predicted by Eq. (1) are shown in the following plots, Fig. 2a and b, for the equivalent strain $\varepsilon_{\mathrm{p}}=0.1$.

For a correct simulation of impact problems, a failure criterion must be used. In the present case, the Johnson Cook failure criterion [32], which is pre-implemented in ABAQUS/Explicit has been used. This criterion is an extension of the formulation proposed by Hancock and Mackenzie [37]. The formulation of the failurecriterion includes strain $\varepsilon^{\mathrm{p}}$, strain rate $\dot{\varepsilon}^{\mathrm{p}}$, and temperature $T$. The failure of material is assumed when the damage parameter $D$ exceeds unity. The $D$ parameter is summed over all increments of plastic deformation. The explicit evolution of $D$ is given by

$$
D\left(\varepsilon^{\mathrm{p}}, \dot{\varepsilon}^{\mathrm{p}}, T, \sigma^{*}\right)=\sum\left(\frac{\Delta \varepsilon^{\mathrm{p}}}{\varepsilon_{\mathrm{f}}^{\mathrm{p}}\left(\dot{\varepsilon}^{\mathrm{p}}, T, \sigma^{*}\right)}\right)
$$

where $\Delta \varepsilon^{\mathrm{p}}$ is an increment of accumulated equivalent plastic strain that occurs during an integration cycle and $\varepsilon_{\mathrm{f}}^{\mathrm{p}}$ is the effective failure strain.

The effective plastic strain at failure $\varepsilon_{\mathrm{f}}^{\mathrm{p}}$ is assumed to depend on the non-dimensional plastic strain rate $\dot{\varepsilon}^{\mathrm{p}} / \dot{\varepsilon}_{0}$, non-dimensional pressure-deviatoric stress ratio $\sigma^{*}=\sigma_{\mathrm{h}} / \sigma$, where $\sigma_{\mathrm{h}}$ is the hydrostatic pressure, and $\sigma$ is the equivalent stress, it depends also on the non-dimensional temperature $T^{*}$, as defined previously. The relation $\varepsilon_{\mathrm{f}}^{\mathrm{p}}=f\left(\sigma^{*}, \dot{\varepsilon}^{\mathrm{p}}, T\right)$ is assumed to be separable and takes the following expression

$$
\left\{\begin{array}{l}
\varepsilon_{\mathrm{f}}^{\mathrm{p}}=\left[D_{1}+D_{2} \exp \left(D_{3} \sigma^{*}\right)\right]\left[1+D_{4} \ln \left(\frac{\varepsilon^{\mathrm{p}}}{\varepsilon_{0}}\right)\right]\left[1+D_{5} T^{*}\right] \\
\sigma^{*}=\frac{1}{3 \sigma}\left(\sigma_{1}+\sigma_{2}+\sigma_{3}\right)
\end{array}\right.
$$

where $D_{i}$ are the failure constants, depending on the materials used. The values used for the material considered $[13,14,33]$ are listed in Table 2 . The failure criterion is based on an equivalent plastic strain $\varepsilon^{\mathrm{p}}$ calculated for each integration point, allowing the elements to be eroded.

The relations of the failure-strain $\varepsilon_{\mathrm{f}}^{\mathrm{p}}$ with the strain rate describing damage of Weldox are shown in Fig. 3. The strain rate only slightly reduces the level of failure-strain for the material considered in this study. The constants which define the failure model were determined without taking into account a temperature effect, $D_{5} \quad 0$, Table 2 .

This kind of fracture criterion based on effective failure-strain is frequently used for impact applications $\left[\begin{array}{ll}11 & 13,20\end{array}\right]$. The criterion is an erosive type and an instantaneous element deletion appears when $D \quad 1$ [38]. When this kind of failure model is applied, the mesh used in the damage zone must be defined with a large 

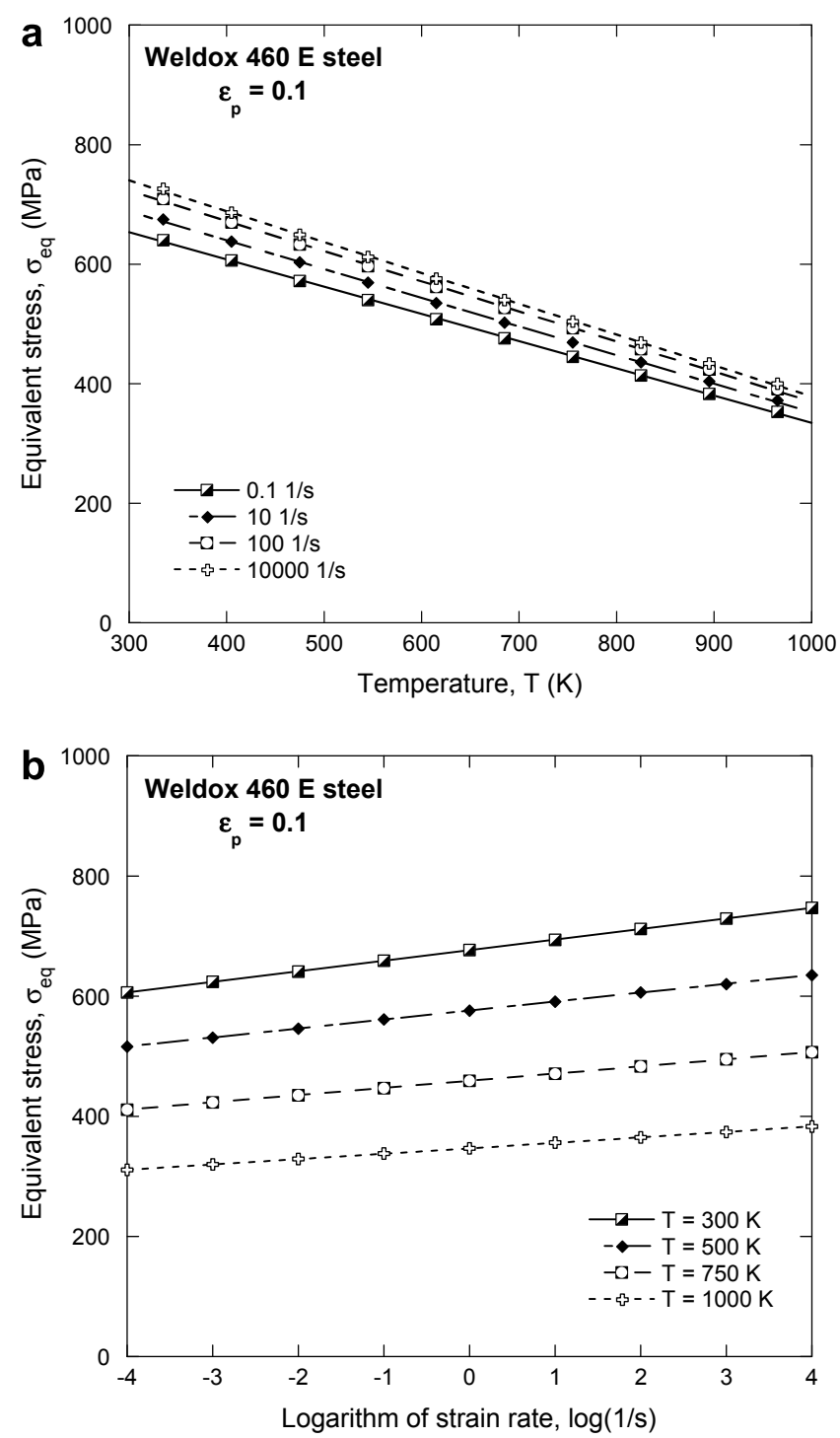

Fig. 2. Temperature (a) and strain rate sensitivity (b) for Weldox $460 \mathrm{E}$ steel for $\bar{\varepsilon}_{\mathrm{p}} \quad 0.1$, Eq. (1).

Table 2

Constants defining the failure model $[13,14,33]$

\begin{tabular}{llccc}
\hline Fracture criterion constants & & & \\
$D_{1}$ & $D_{2}$ & $D_{3}$ & $D_{4}$ & $D_{5}$ \\
0.0705 & 1.732 & 0.54 & 0.0123 & 0 \\
\hline
\end{tabular}

density, in order to not affect the numerical results in terms of energy lost. An alternative solution, which is not considered here, is the approach by the failure strain along with the use a cohesive element allowing to propagate failure process $[39,40]$. However, this technique is well suited for brittle materials and not for a ductile behaviour.

\section{Numerical configuration}

The FE code used in this study to perform the numerical simulations is ABAQUS/Explicit, allowing efficient reproduction of the dynamic loading processes as impact events, for example $[1113,41,42]$. The 


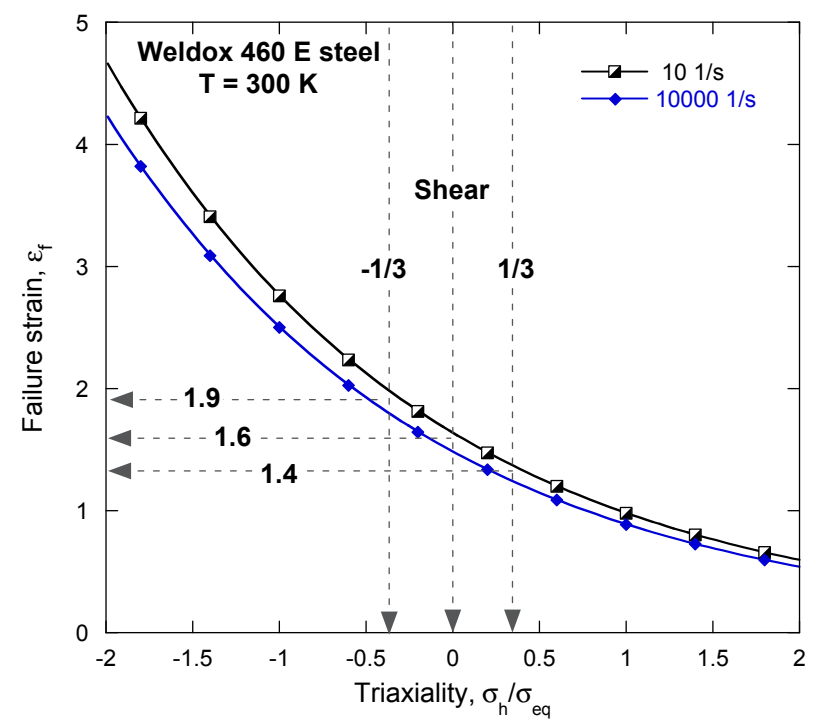

Fig. 3. Failure strain versus stress triaxiality for Weldox 460 E steel, Eq. (5).

numerical configuration is based on the experimental arrangement by Borvik et al. [9], where a circular clamped plate receives perpendicular impact by a conical non-deformable projectile launched in a wide range of impact velocities. An axi-symmetric configuration has been used to reproduce these experiments [ 10 14], Fig. 4. Several projectile shapes have been used for the same plate configuration. The friction coefficient used during numerical simulations is $\mu \quad 0.1$. The dynamic friction has been studied and reported in $[13,20]$. In the present paper, some comments are also addressed as to the temperature increase during complete perforation.

\subsection{Projectile characterization}

The projectile is defined as a rigid body in ABAQUS notation [38], allowing an appreciable reduction in calculation time. This definition is in agreement with the mechanical properties of the projectiles defined in [9]. In the experimental study reported in [9], the projectiles after machining were oil quenched to reach the HRC of $R_{\mathrm{c}} 53\left(\sigma_{y} \approx 1900 \mathrm{MPa}\right)$. This operation allowed for reduction of the plastic deformation and erosive process of the projectile during perforation. The projectiles used during numerical simulations are shown in Fig. 5. The projectile mass: $M_{\mathrm{p}} \quad 0.2 \mathrm{~kg}$ and the nose angle $\Theta \quad 18.5^{\circ}$ are the same in all numerical

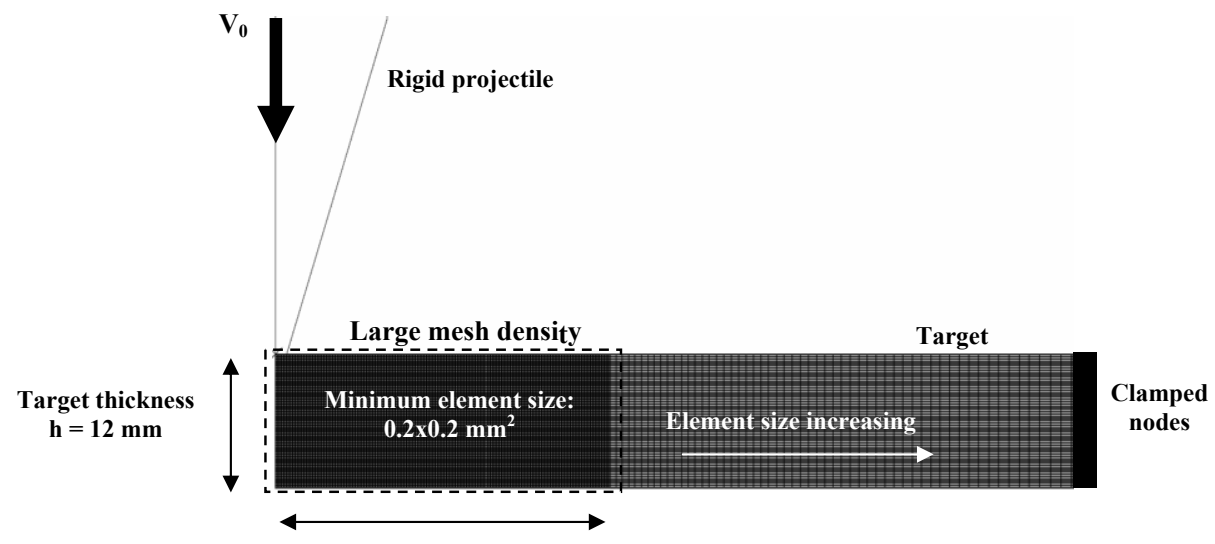

Fig. 4. Axi symmetric mesh configuration used. 


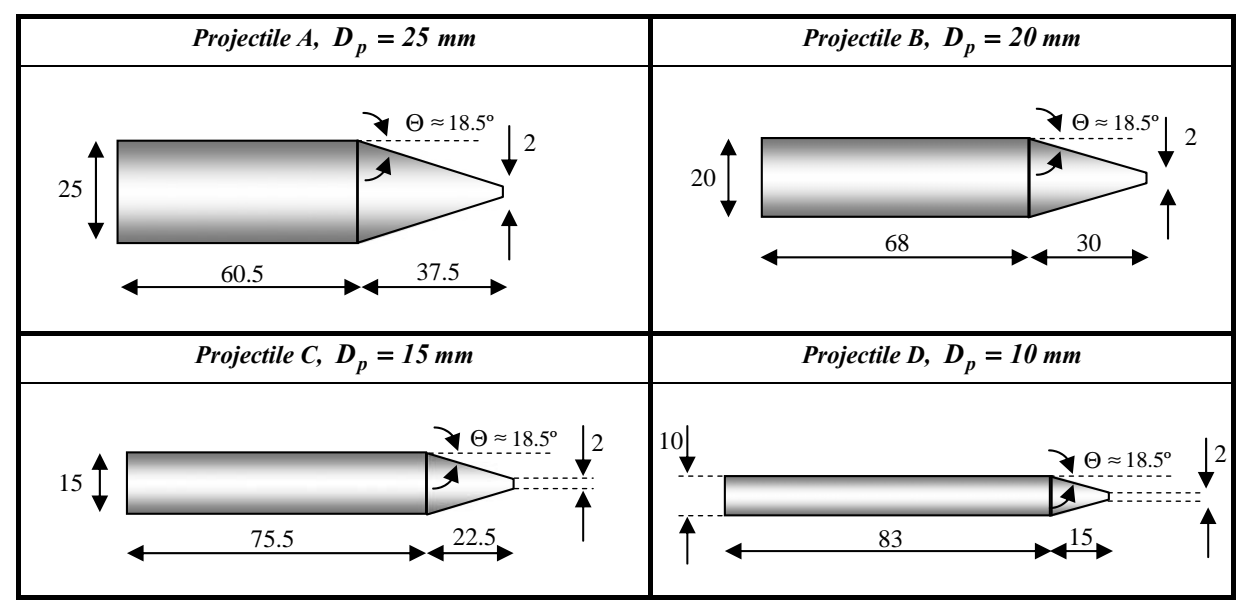

Fig. 5. Projectile shapes applied during the numerical simulations (dimension in millimeters).

simulations. The projectile diameters $D_{\mathrm{p}}$, were changed from $D_{\mathrm{p}} \quad 25 \mathrm{~mm}$ to $D_{\mathrm{p}} \quad 10 \mathrm{~mm}$ with an interval decrease of $5 \mathrm{~mm}$ between each configuration.

The modification of the projectile calibre, Fig. 6a, induces a change in the nose area $A_{\mathrm{c}}$, which is defined for different configurations by Eq. (6)

$$
A_{\mathrm{c}}=\frac{\pi \cdot D_{\mathrm{p}}^{2}}{4 \cdot \sin \Theta}
$$

The evolution of the nose area with the projectile nose length $l$ is shown in Fig. 6b. Thus, the projectile nose surface $A_{\mathrm{c}}$ in contact during the perforation process increases to the second power with $l$, Fig. $6 \mathrm{~b}$.

\subsection{Target}

The target thickness and the target diameter are assumed respectively as $h \quad 12 \mathrm{~mm}$ and $d \quad 500 \mathrm{~mm}$. The plate has been meshed with CAX4R elements available in ABAQUS-Explicit. The zone affected by the
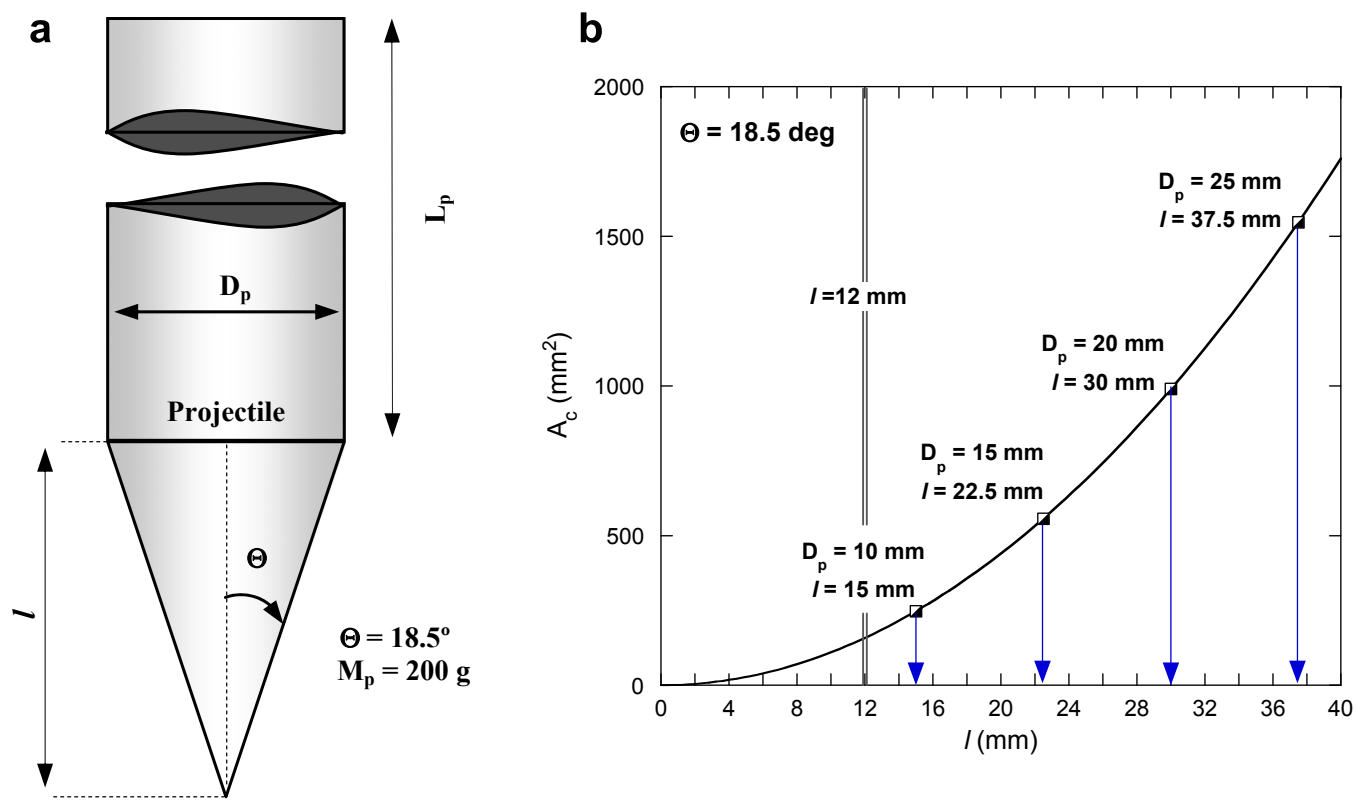

Fig. 6. (a) Geometrical parameters of projectile and (b) nose area increase with projectile diameter. 
perforation process was meshed with smaller-size elements $0.2 \times 0.2 \mathrm{~mm}^{2}$, Fig. 4 . This element size has been previously used by Arias et al. [13] for the same configuration. The ratio of the elements employed, 1:1, satisfies the conditions introduced by Zukas and Scheffler [43].

\subsection{Adaptive meshing}

Gupta et al. [11,12] and Arias et al. [13] describe an advantage of using the adaptive meshing algorithm available in ABAQUS/Explicit for analyses of plate-impact events. This approach minimizes the problem of element distortion frequently appearing under dynamic loading. The scheme of the adaptive mesh available in ABAQUS combines the features of pure Lagrangian and pure Eulerian analyses, in which the mesh is fixed spatially and the material flows through the mesh. The implementation of this algorithm allows for obtaining a high mesh quality during the complete time of calculation. In an adaptive mesh increment, a new smoother mesh is created by sweeping iteratively over the adaptive mesh domain. During each mesh sweep, nodes in the domain are relocated based on the current positions of neighbouring nodes and elements to reduce element distortion [38]. In a typical sweep, a node is moved as a fraction of the characteristic length of any element surrounding the node. Values between 30 and 60 mesh sweeps were used during numerical simulations.

Therefore this technique makes it possible to maintain the element-aspect ratio approximately constant during simulation, and the angle between the neighbouring elements remains consistently close to its original value, Fig. 7. This technique facilitates the interpolation necessary to determine the output field variables, thereby reducing the time of calculation.

Two different zones of the target mesh during perforation are shown, Fig. 7. These parts refer to the target zones strongly affected by plastic strain gradients and are therefore susceptible to have an element-distortion problem. However, as it can be seen, the elements remain close to their original size for both situations. Moreover, the ALE approach reduces the number of elements eroded during the penetration process. Thus, the energy balance is preserved, notably reducing errors in estimating the residual velocity.

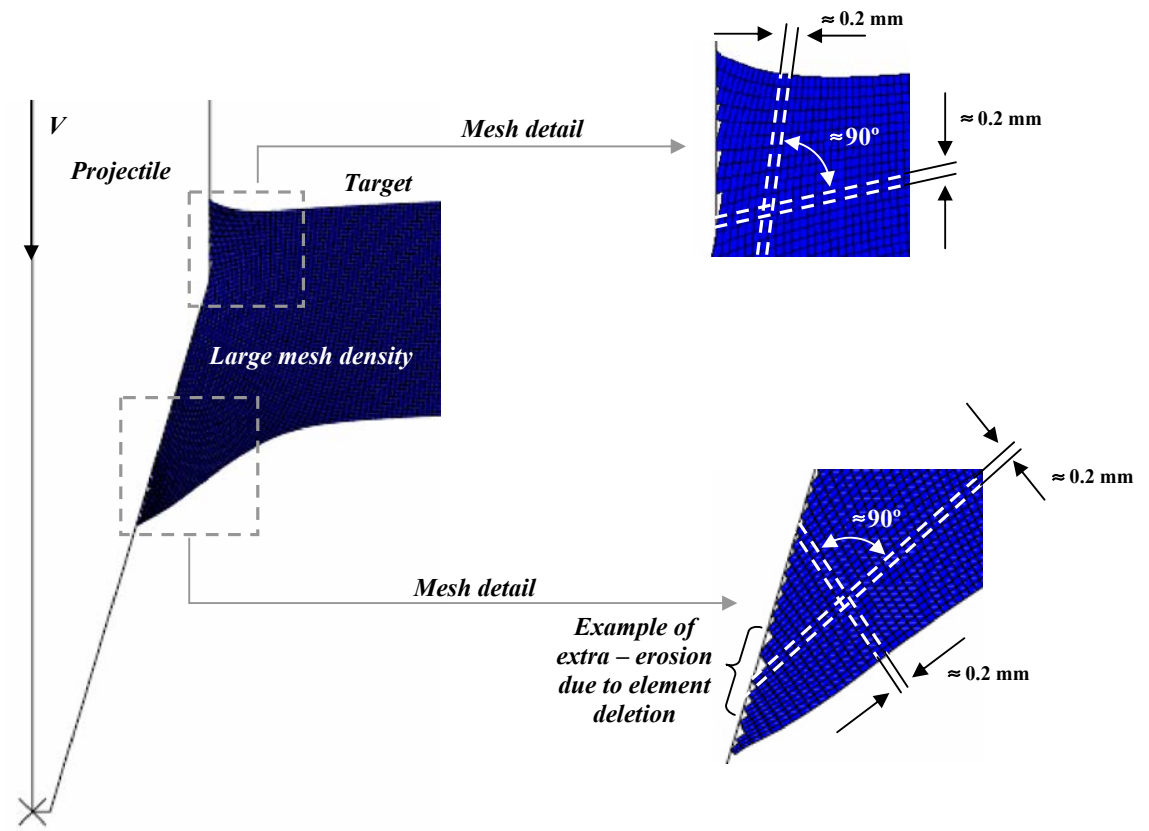

Fig. 7. Advantage of ALE scheme using erosive configuration. 


\subsection{Model validation}

The numerical configuration used has been previously applied in [13] and validated by experimental data reported in [9] to reproduce the penetration process by different nose shapes: cylindrical, hemispherical and conical. In this previous work [13], the failure modes associated with each projectile nose shape, included conical configuration were successfully verified. In the present work, the same Weldox steel plate has been assumed ( $h \quad 12 \mathrm{~mm}$ ) and the same mass $M_{\mathrm{p}} \quad 0.2 \mathrm{~kg}$. for the conical projectiles is assumed. During the numerical simulations the mass of projectile was always assumed the same independently of the projectile shape.

Figs. 8 and 9 show the data plot of residual velocity $V_{\mathrm{r}}$ versus failure time $t_{\mathrm{f}}$ obtained during numerical simulations and compared with experiment reported in [9]. The failure time is defined as the time to perforate completely the target. However, for low impact velocity, the failure time is defined using the maximum force

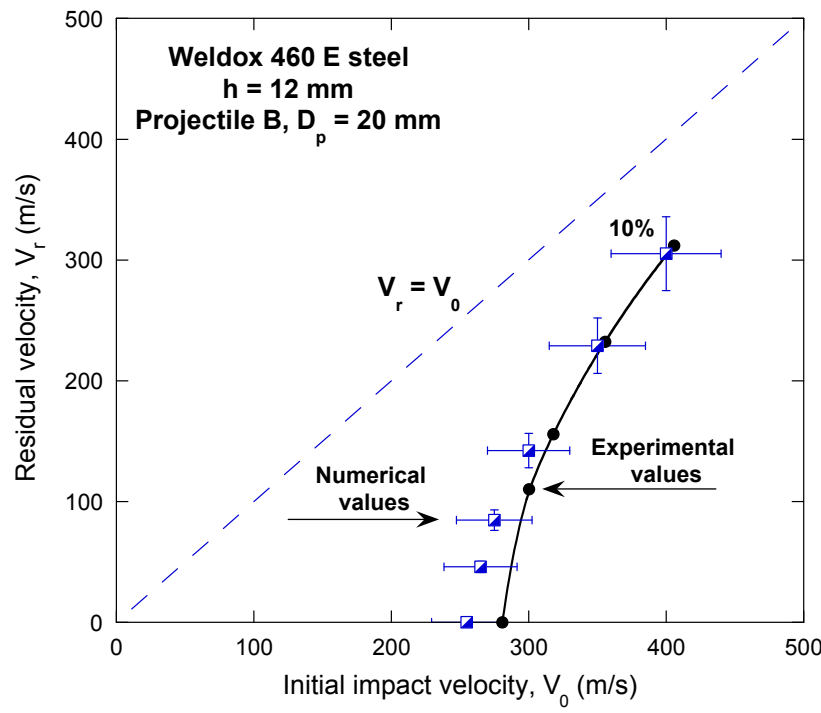

Fig. 8. Numerical results on residual velocity: comparison with experimental data for projectile $\mathrm{B}, D_{\mathrm{p}}=20 \mathrm{~mm}$.

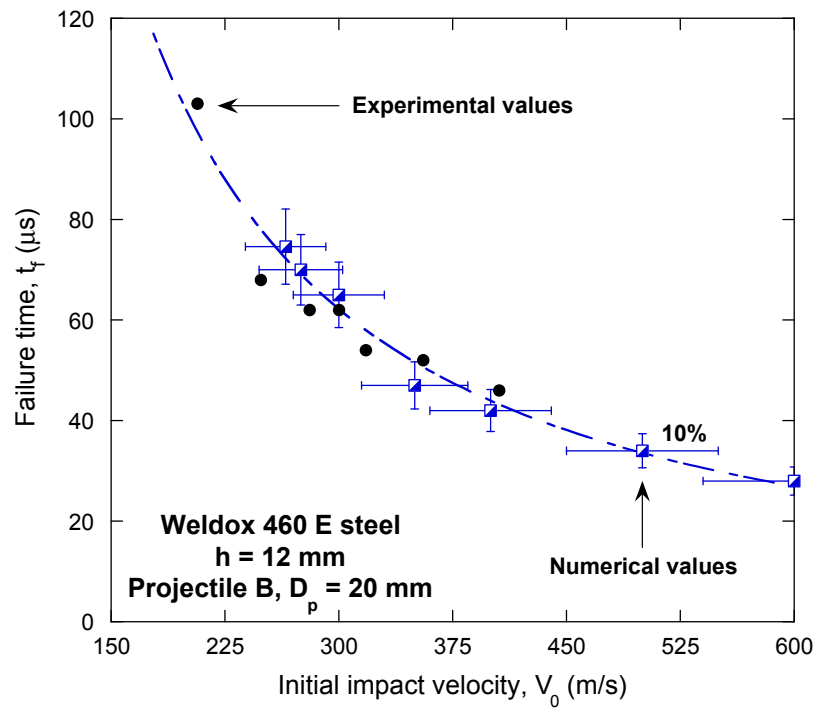

Fig. 9. Numerical results of failure time: comparison with experimental data for Projectile $\mathrm{B}, D_{\mathrm{p}}=20 \mathrm{~mm}$. 
level [20]. Numerical estimations are in agreement with experimental results with maximum difference of $10 \%$. A similar scatter is frequently reported as for example in $[9,11 \quad 13]$. The slightly larger values found by numerical simulations are certainly due to the definition of the projectile as rigid body. This assumption prevents the energy absorption by the projectile during penetration. In several works $[44,45]$ the projectile behaviour is commonly defined as simply elastic or elastic perfectly plastic without using a failure criterion. In present case, the definition of rigid body changes the numerical predictions concerning the residual velocity. In the range of $V_{0}>400 \mathrm{~m} / \mathrm{s}$ it would be expected that the projectile would be deformed plastically during perforation [46,47]. However, the absence of experimental data for this range of impact velocity, $V_{0} \geqslant 400$, does not permit to carry out a precise analysis concerning such possibility.

Moreover, projectile deviation from the axis at high impact velocity has not been observed since this effect appears at very high impact velocity, usually higher than $1000 \mathrm{~m} / \mathrm{s}$ as it was recently reported by [48]. At very high impact velocity, due to projectile deviation a cavity expansion process appears due to inertia effect. This effect changes for example the shape of hole after complete perforation process. In the following section a complete analysis is offered with different projectile diameters $D_{\mathrm{p}}$ by assumption of a constant initial kinetic energy $K_{\mathrm{p}}$.

\section{Analysis}

Greater projectile calibre induces a larger plastic zone directly affected by impact. At the same time, the projectile-nose surface area in contact with the plate during perforation increases. These effects increase the resistance of the plate to perforation. Thus, the first target in the analysis is to compare the force of perforation for a fixed impact velocity, $V_{0} 500 \mathrm{~m} / \mathrm{s}$, Fig. 10. This comparison reveals how the force of perforation augments with the projectile calibre. It is observed that the force increases with time, defined as the slope $\alpha$, is a constant without dependency on the projectile diameter until maximum force stage, Fig. 10. The parameter $\alpha$ depends on the impact velocity.

In conclusion, the energy lost by the projectile, $\Delta K_{\mathrm{p}}$, Eq. (7), increases with the projectile calibre, Fig. 11.

$$
\Delta K_{\mathrm{p}}=\frac{1}{2} \cdot M_{\mathrm{p}} \cdot\left(V_{\mathrm{r}}^{2}-V_{0}^{2}\right)
$$

For the projectile configurations considered the plate absorbs less energy when the initial impact velocity increases, Fig. 11. This trend can be also observed in Fig. 12, where $\partial V_{\mathrm{r}} / \partial V_{0}>1$ for all projectiles and initial impact velocities analysed.

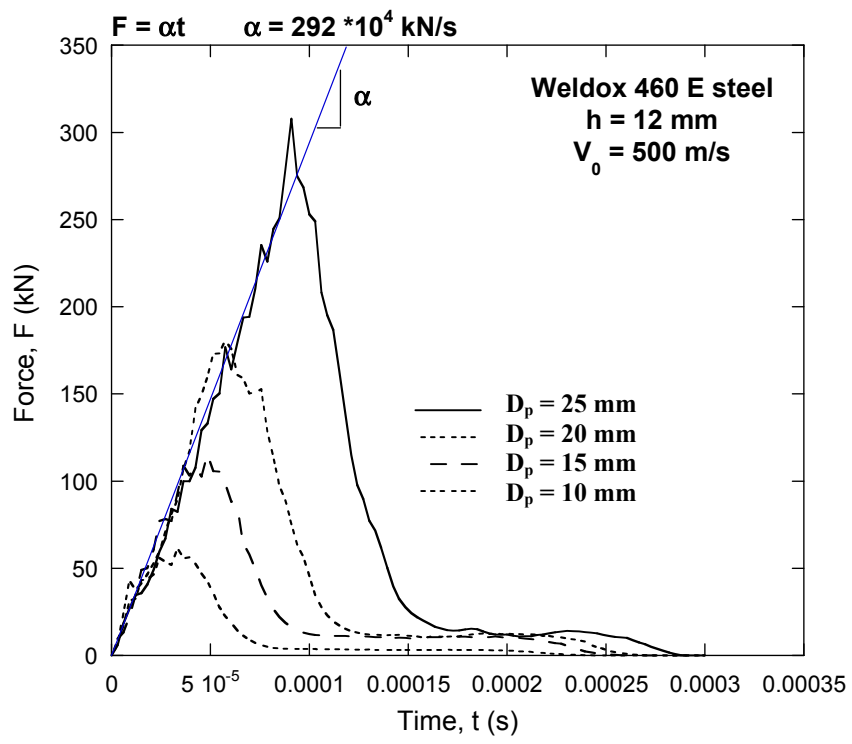

Fig. 10. Evolution of force versus time, $V_{0}=500 \mathrm{~m} / \mathrm{s}$. 


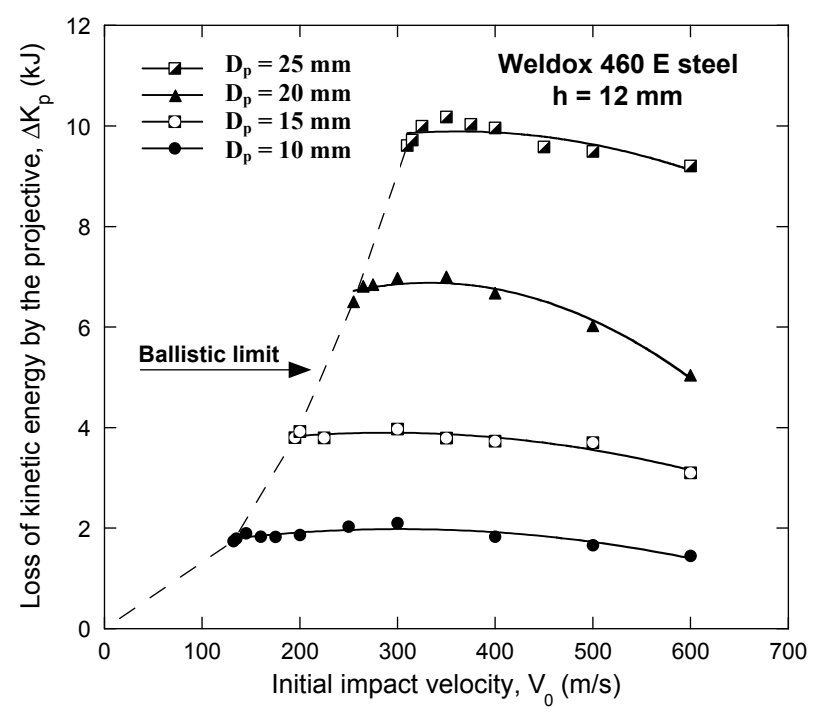

Fig. 11. Loss of kinetic energy by projectiles versus impact velocity.

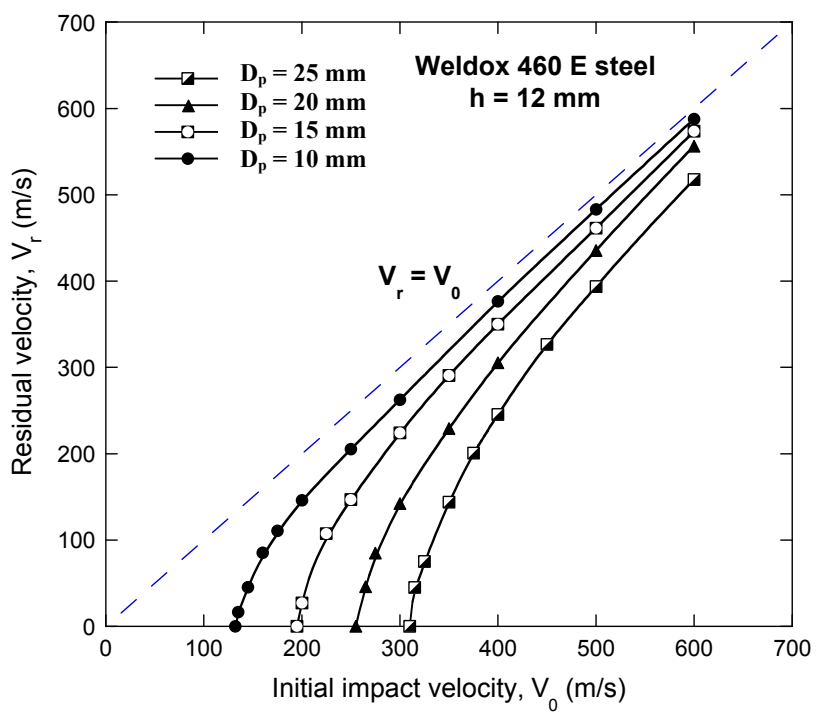

Fig. 12. Numerical estimation of the residual velocity for all the projectiles considered.

However, for initial impact velocities close to $V_{0} \quad 1000 \mathrm{~m} / \mathrm{s}$ it has been observed that $\partial V_{\mathrm{r}} / \partial V_{\mathrm{o}} \leqslant 1$. This behaviour is induced by the predominance of inertial effects when a certain level of impact velocity is reached [20]. Thus, when cylindrical or hemispherical projectiles are used, the energy lost by the projectile increases with impact velocity from the ballistic limit velocity value $[9,13,20]$. In this case inertial effects are relevant for the whole range of impact velocity due to plug ejection as final stage of the perforation process.

In Fig. 13 the results are shown that the velocity lost by the projectile increases as a square root of the projectile diameter, $\left(V_{0}-V_{\mathrm{r}}\right) \propto D_{\mathrm{p}}^{1 / 2}$, or in other words, the velocity lost by the projectile is directly proportional to the projectile-nose area, $\left(V_{0}-V_{\mathrm{r}}\right) \propto A_{\mathrm{c}}$.

Therefore, the velocity lost by the projectile has been found constant per unit nose area for each initial impact velocity. Thus, it is possible to establish a relation with the initial impact velocity as a power law, Fig. 14. The result allows for estimating the residual velocity for any other initial impact velocity and projectile diameter by using the projectile mass and nose angle considered in this work. 


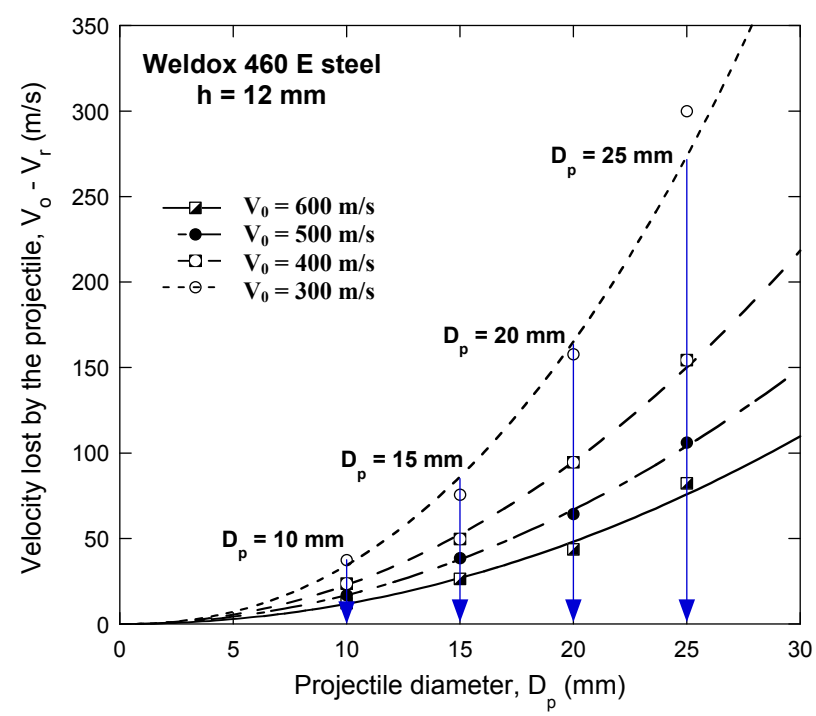

Fig. 13. Velocity lost by the projectile for several initial impact velocities.

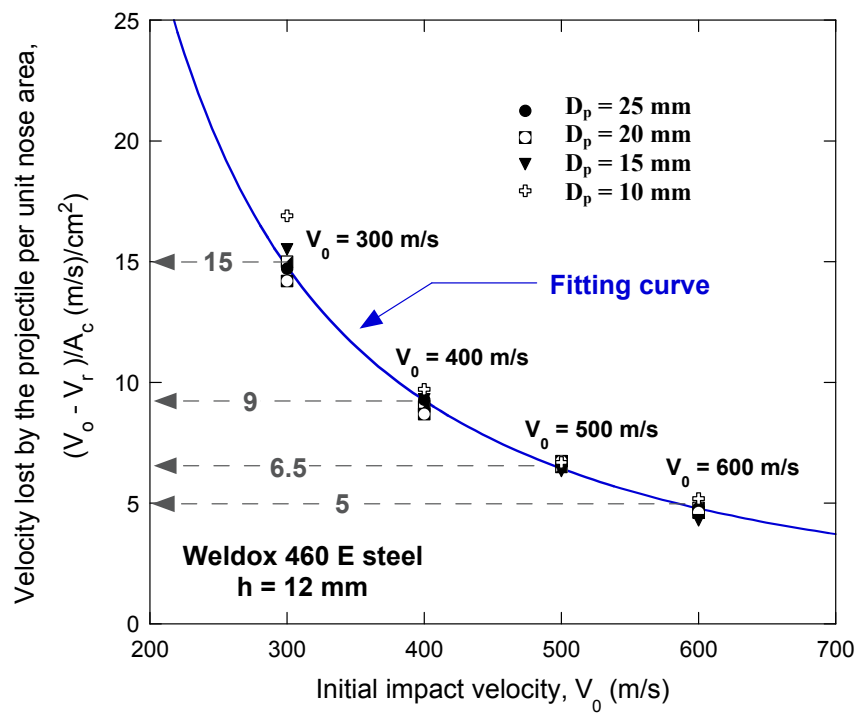

Fig. 14. Evolution of the velocity lost by the projectile per unit nose area with initial impact velocity.

In addition, it is interesting to evaluate the effect of the projectile calibre on the ballistic limit for each configuration. Close to the ballistic limit condition, a strong gradient is found in terms of residual velocity with projectile diameter increase. For example, for $D_{\mathrm{p}} \quad 25 \mathrm{~mm}$ the velocity difference is from $V_{0} \quad 315 \mathrm{~m} / \mathrm{s}$ to $V_{\mathrm{r}} 10 \mathrm{~m} / \mathrm{s}$ and for $D_{\mathrm{p}} \quad 10 \mathrm{~mm}$ from $V_{0} \quad 135 \mathrm{~m} / \mathrm{s}$ to $V_{\mathrm{r}} \quad 10 \mathrm{~m} / \mathrm{s}$. Thus, the perforation process is more efficient for small diameters since, as previously reported, less kinetic energy is lost. In this case the ballistic limit is lower in comparison to projectiles of larger diameters (see Fig. 15).

The relationship between the projectile calibre and the ballistic limit is shown in Fig. 16, revealing that the ballistic limit increases linearly with the projectile diameter, $V_{\mathrm{bl}} \propto D_{\mathrm{p}}$. Additionally, this relation has been also numerically validated for projectile diameters $D_{\mathrm{p}} \quad 30 \mathrm{~mm}$ and $D_{\mathrm{p}} \quad 35 \mathrm{~mm}$. Therefore, according to Eq. (6) the ballistic limit evolves as a power law with the nose area: $V_{\mathrm{bl}}^{1 / 2} \propto A_{\mathrm{c}}$.

The same conclusion about the ballistic limit evolution with projectile diameter can be obtained by a analytical approach by considering the ballistic limit condition shown in Fig. 17. It is possible then to define the total amount of energy absorbed by the plate using the relation in the form of Eq. (8). 


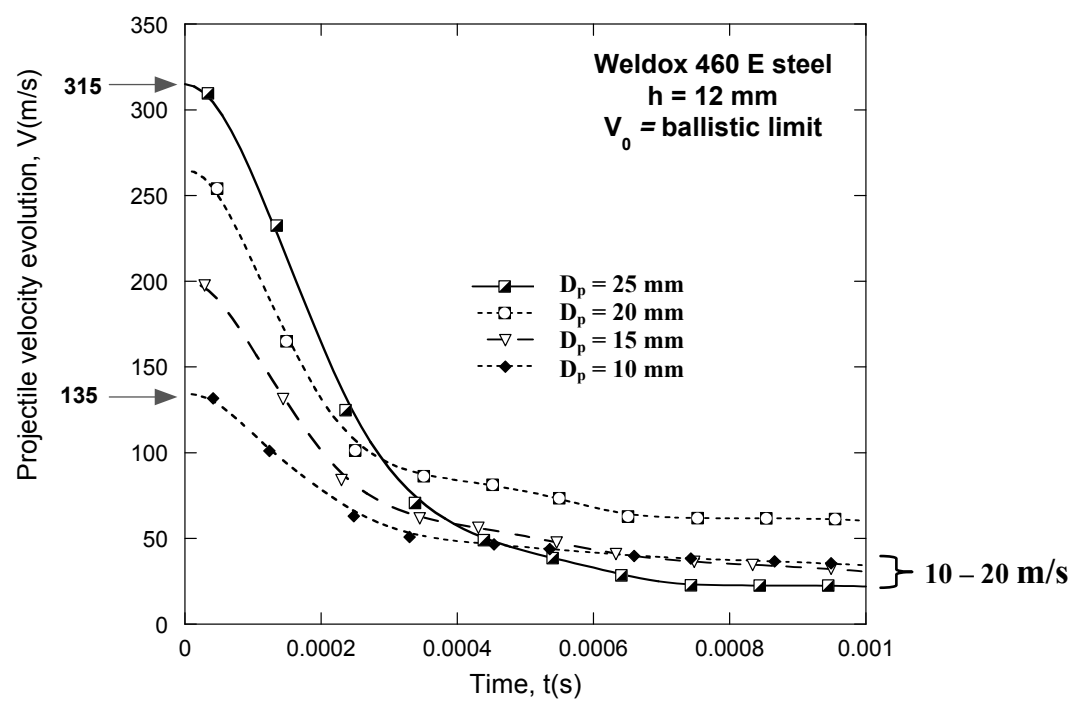

Fig. 15. Velocity evolution at the ballistic limit for each nose configuration.

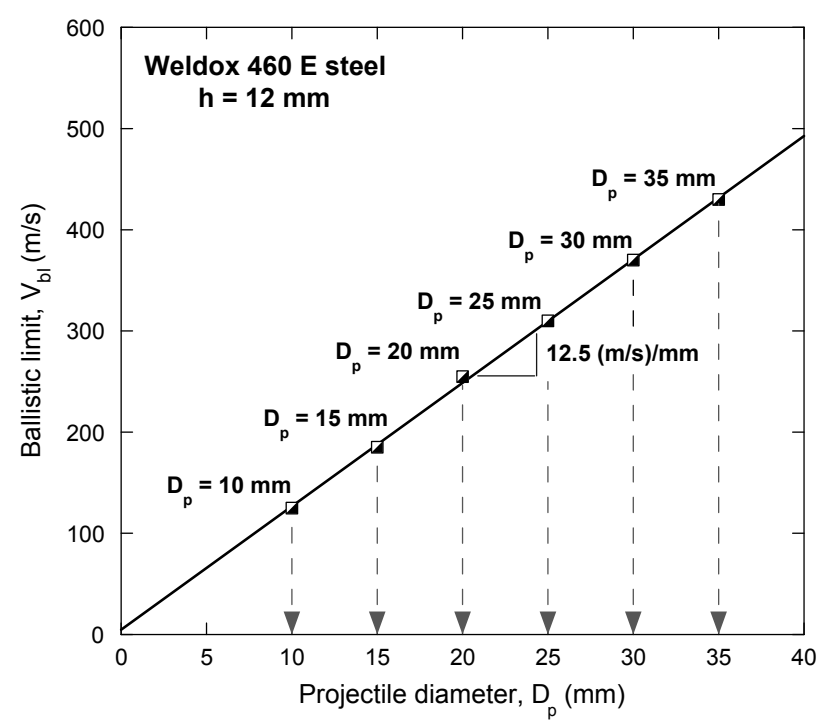

Fig. 16. Variation of ballistic limit with projectile diameter.

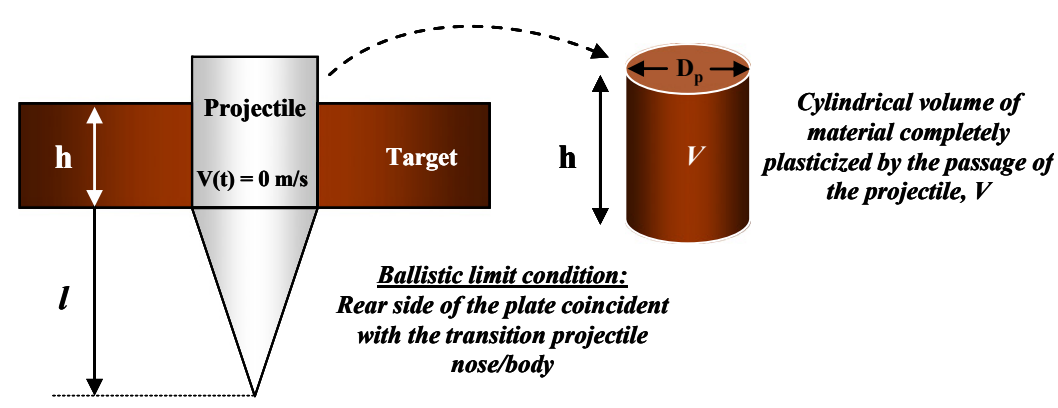

Fig. 17. Definition of the ballistic limit condition and the volume completely plasticized by the passage of the projectile. 


$$
\Delta K_{\mathrm{p}}=\frac{1}{2} \cdot M_{\mathrm{p}} \cdot V_{\mathrm{r}}^{2}+\Delta W
$$

As reported in [20] the energy absorbed by the plate can be decomposed as follows

$$
\Delta W=W_{\mathrm{p}}+W_{\mathrm{f}}+W_{t p}
$$

where, $W_{\mathrm{p}}$ is the plastic work, $W_{\mathrm{f}}$ is the friction work and $W_{\mathrm{tp}}$ is the kinetic energy transferred to the plate representing the inertial effects. Specifying this expression for the ballistic limit condition the terms corresponding to $W_{\mathrm{f}}$ and $W_{\mathrm{tp}}$ can be neglected in comparison with $W_{\mathrm{p}}[20]$. Thus, Eq. (9) can be rewritten as follows

$$
\Delta W=W_{\mathrm{p}}=\frac{1}{2} \cdot M_{\mathrm{p}} \cdot V_{\mathrm{bl}}^{2}
$$

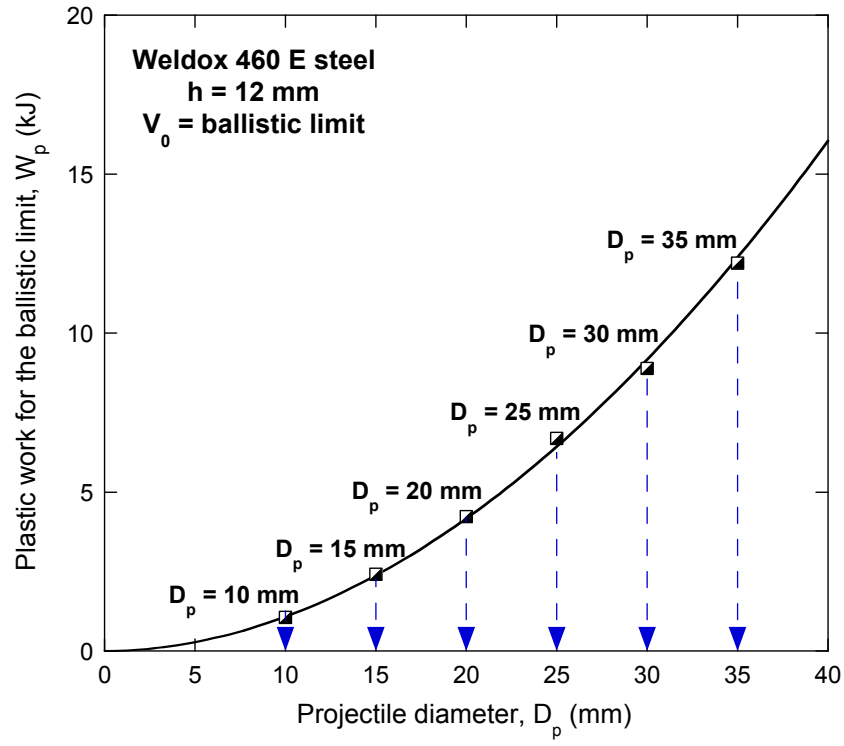

Fig. 18. Plastic work evolution with the ballistic limit.

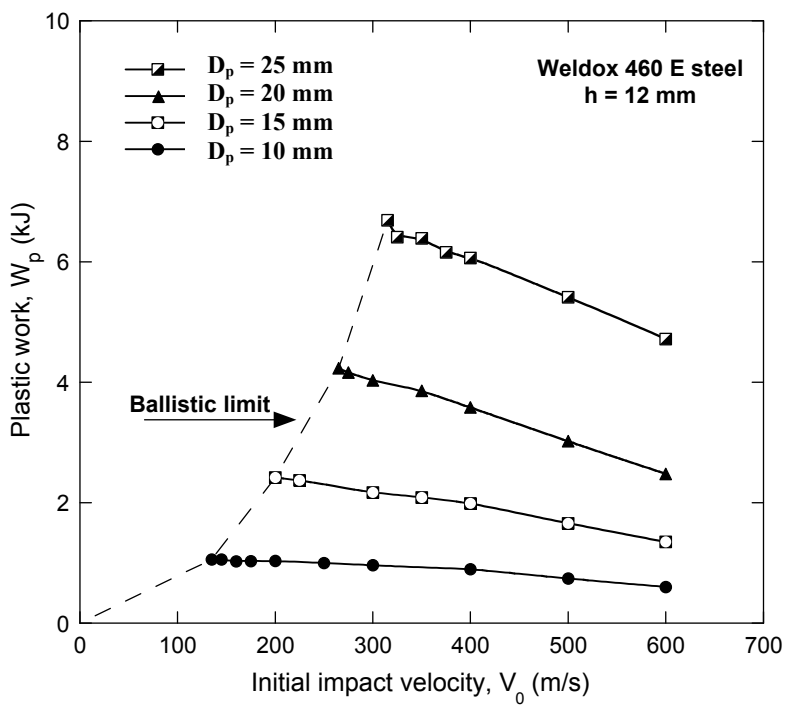

Fig. 19. Plastic work evolution with initial impact velocity. 
In order to facilitate the analytical approach by neglecting the strain hardening and thermal effects [33], the plastic work is defined in Eq. (11).

$$
\left.W_{\mathrm{p}}\right|_{\varepsilon, T}=V \int_{\varepsilon_{e}}^{\varepsilon_{\max }} \sigma \mathrm{d} \varepsilon=\sigma \cdot \pi \cdot \frac{D_{\mathrm{p}}^{2}}{4} \cdot h \cdot \Delta \varepsilon \propto D_{\mathrm{p}}^{2}
$$

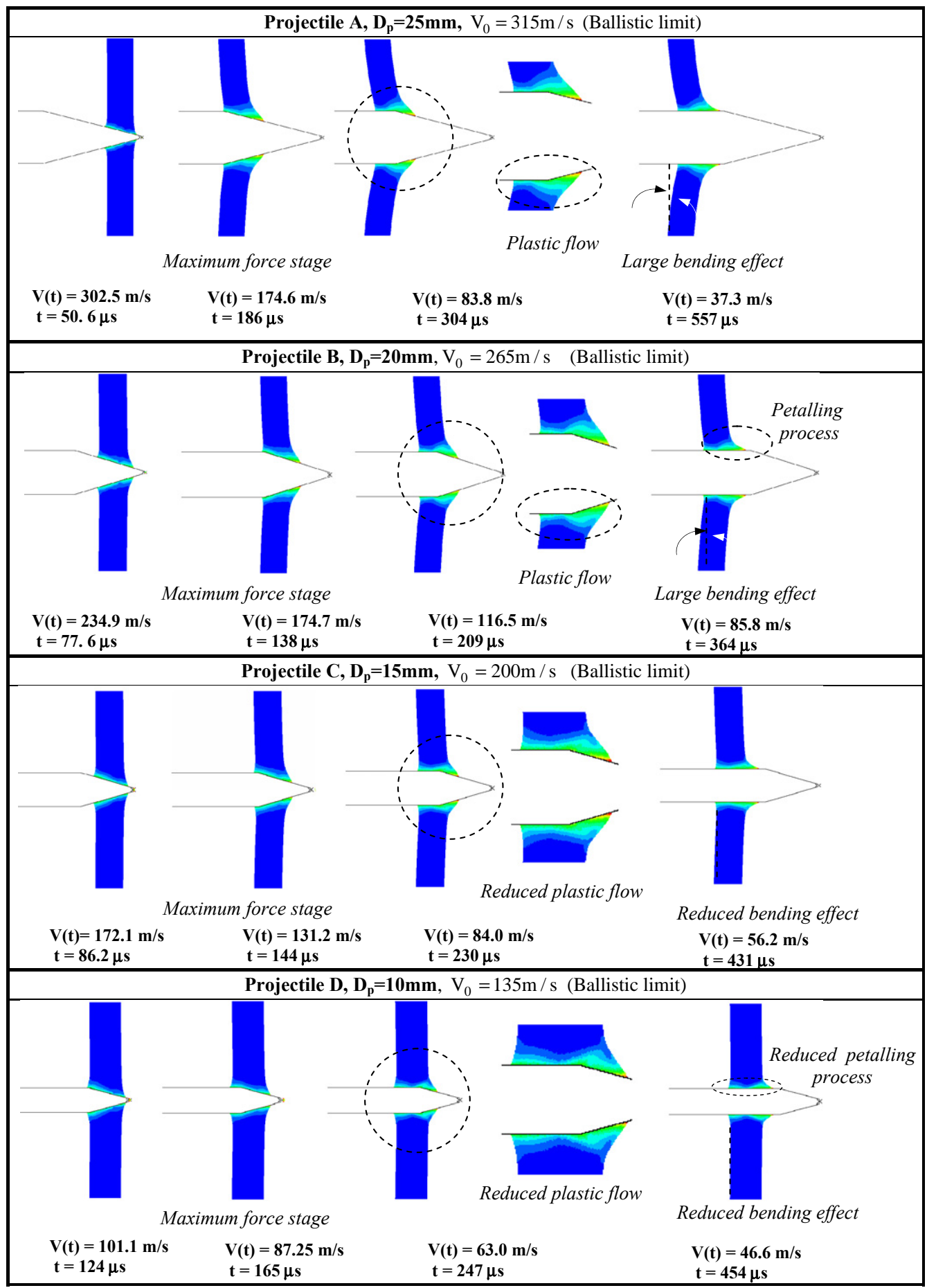

Fig. 20. Equivalent plastic strain contours during the perforation process for each nose shape. 
where $\sigma$ is the flow stress allowing definition of the plastic behaviour without hardening. The material is simply considered as perfectly plastic, since it is observed that in dynamic loading due to heat generation that the hardening rate is close to zero. This formulation is based on a simple assumption considering a cylinder
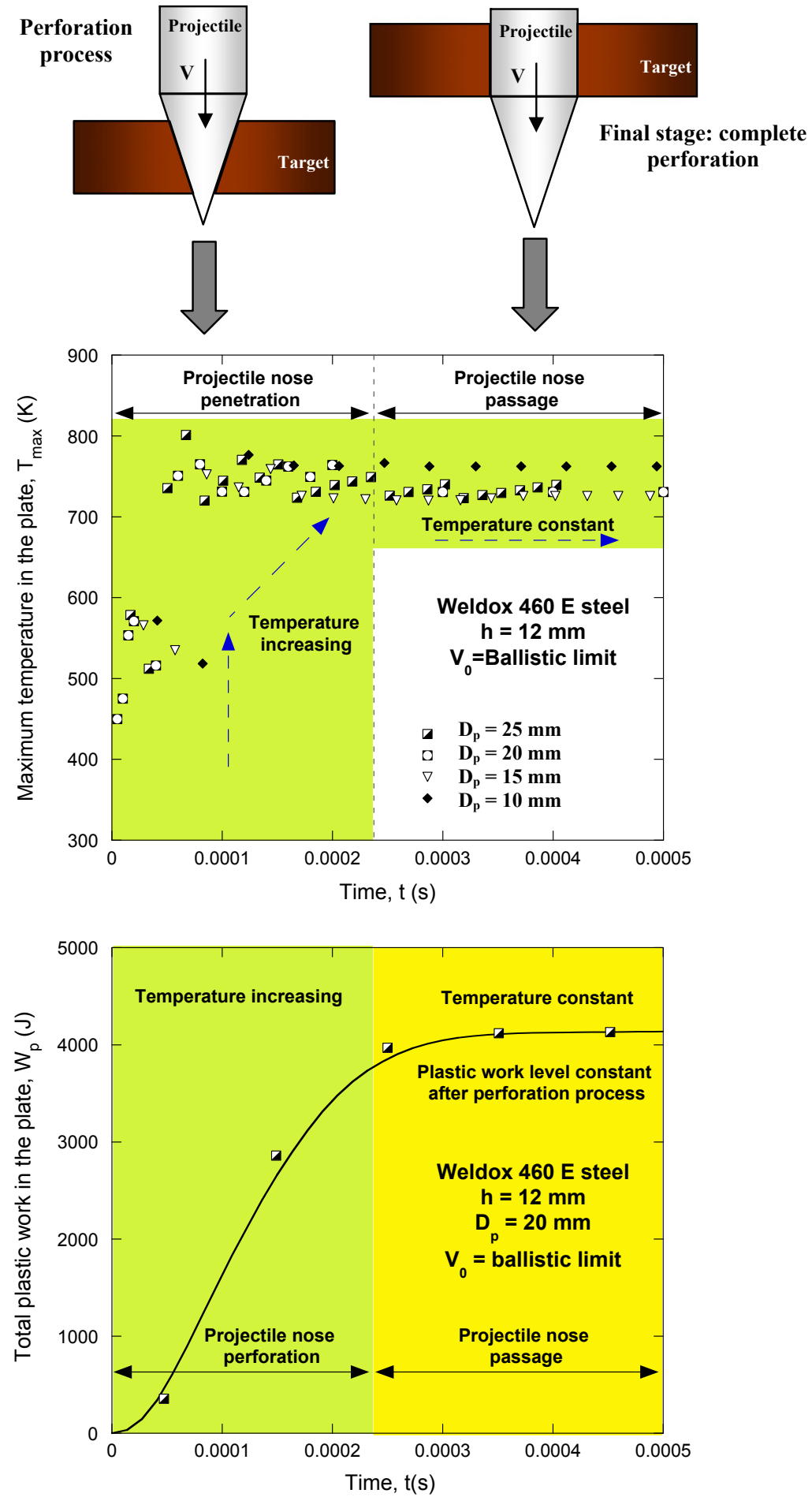

Fig. 21. Temperature and plastic work evolution in time during perforation. 
deformed plastically, Fig. 17. It is observed that the plastic work increases with the second power of diameter, $W_{\mathrm{p}} \propto D_{\mathrm{p}}^{2}$. This tendency is observed numerically as shown in Fig. 18.

By comparing Eqs. (10) and (11) the following relation is found, Eq. (12). It is observed that the ballistic limit is proportional to the projectile diameter with a linear tendency.

$$
\begin{aligned}
& \frac{1}{2} \cdot M_{\mathrm{p}} \cdot V_{\mathrm{bl}}^{2}=\sigma \cdot \pi \cdot \frac{D_{\mathrm{p}}^{2}}{4} \cdot h \cdot \Delta \varepsilon \\
& V_{\mathrm{bl}}=D_{\mathrm{p}}\left(\frac{\pi}{2} \frac{\sigma}{M_{\mathrm{p}}} h \Delta \varepsilon\right)^{1 / 2}
\end{aligned}
$$

The simple analytic expression for the ballistic limit is therefore given by Eq. (13). Thus, it is confirmed confirms the linear relation found numerically, $V_{\mathrm{bl}} \propto D_{\mathrm{p}}$.

Concerning plastic work, it is observed, Fig. 19, that an increase of the initial impact velocity reduces the plastic zone due to fast damage localization $[13,20]$.

In relation to the effect of the projectile calibre in terms of the level of plastic work, it is shown that large projectile diameter induces a high plastic work, Fig. 19. This effect can be explained by the increase of the size of the affected zone with the augment of the projectile calibre, Fig. 20. A larger bending effect is observed as the projectile diameter increases, Fig. 20, inducing a higher dissipation of plastic work.

The nose-projectile shape has an effect on the temperature increase as it is reported for example in $[9,13]$. The main objective of this kind of analysis is to observe thermal softening effect responsible for apparition of instabilities in the failure mode $[20,49,50]$. In the present case, the influence of conical projectile diameter on the temperature increase has been considered using the same failure strain level. The analysis shows relevant conclusions concerning the plastic strain field imposed into the plate. This was possible since in adiabatic conditions the temperature increase is directly linked to plastic strain.

Concerning the temperature evolution in the plate shown in Fig. 21, two distinct phases can be defined: the first one corresponds to initial penetration of the projectile into the plate, while the second one refers to the complete perforation through the target. In the first phase (left-hand side of Fig. 21) the temperature increases with the displacement of material during perforation due to plastic flow. In the second phase (right-hand side of Fig. 21) the temperature remains constant since the variation of plastic work is negligible.

Fig. 22 shows that the temperature level does not depend on the projectile diameter. Therefore, the maximum plastic deformation in the elements is approximately constant throughout the process.

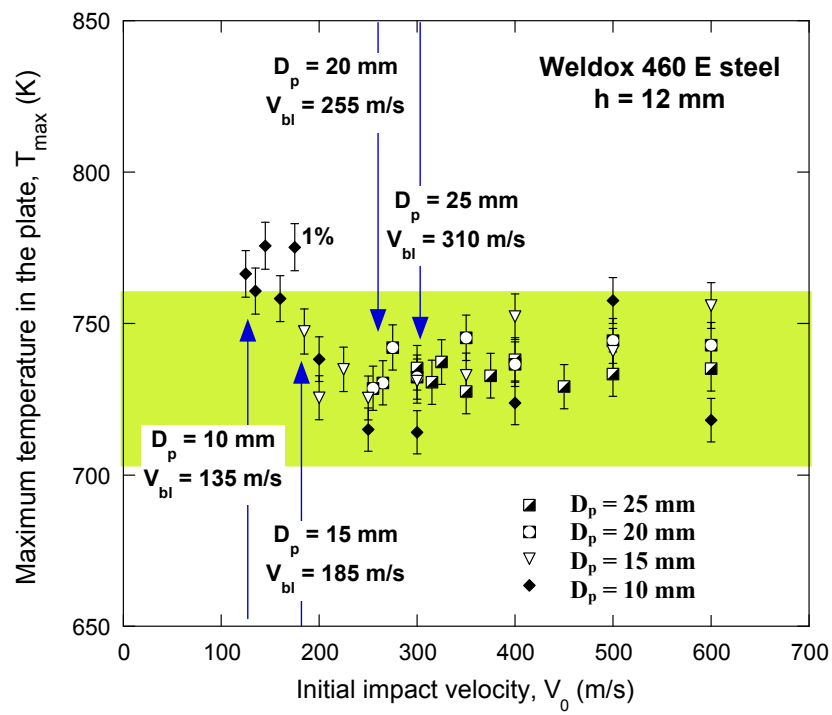

Fig. 22. Maximum temperature estimations. 
The plastic strain field induced in the plate strongly depends on the nose-projectile shape and the associated failure mode $[9,13]$. However, in the present case, with a fixed nose shape, the plastic strain field is not strongly affected by the nose area. In other words, in order to observe a variation of the plastic field in the plate for an impact velocity imposed, the failure mode must be changed.

The maximum temperature reached is close to $T_{\max } \approx 750 \mathrm{~K}$. This temperature agrees with the numerical values reported in [10] for the same projectile-plate configuration. According to Fig. 2a such temperature increase induces a considerable softening of the target material. A precise analysis concerning the thermal effect in formation of petalling, when mild steel plates are subjected to perpendicular impact by hemispherical projectiles, can be found in [20].

A decrease of the estimated temperature can be noted for $D_{\mathrm{p}} \quad 10 \mathrm{~mm}$, Fig. 22. This effect is due to element erosion during perforation time. In fact, during an early perforation time, the temperature increases strongly in some elements due to excessive plastic deformation. Afterwards, when the failure criterion is reached, the elements are deleted, and the maximum local plastic deformation level observed in the plate is reduced. By applying of failure criterion a decrease of temperature is observed after deletion of first elements. However, for every case considered the average value of the maximum temperature is limited to $705 \mathrm{~K}<T_{\max }<755 \mathrm{~K}$.
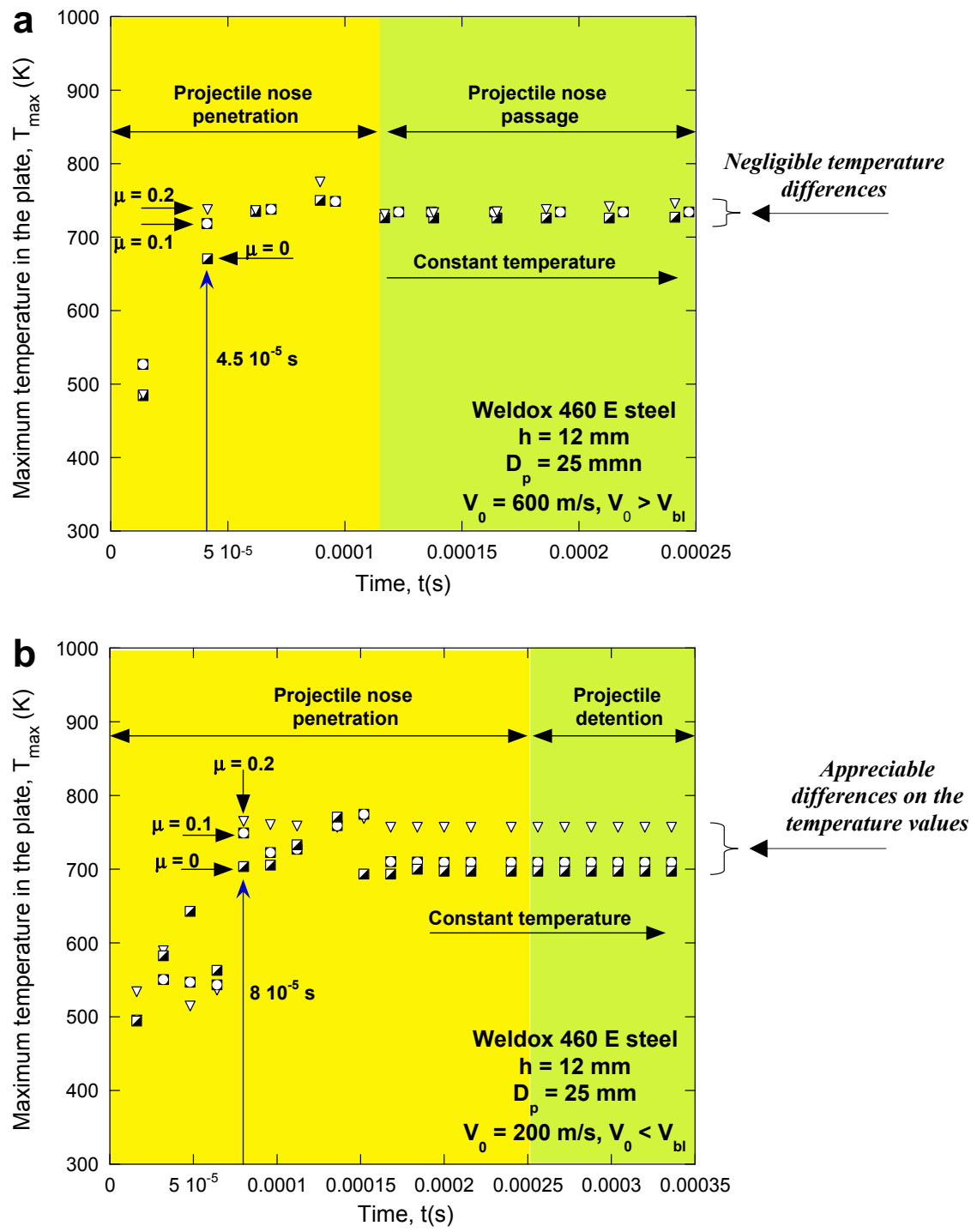

Fig. 23. Maximum temperature evolution: (a) $D_{\mathrm{p}}=25 \mathrm{~mm}, V_{0}=600 \mathrm{~m} / \mathrm{s}$; (b) $D_{\mathrm{p}}=25 \mathrm{~mm}, V_{0}=200 \mathrm{~m} / \mathrm{s}$. 
Fig. 23 shows temperature level evolution with time for different friction coefficients, from $\mu \quad 0$ to $\mu \quad 0.2$. The friction effect is more important during the pre-perforation. Thus, for $t 4.5 \times 10^{5} \mathrm{~s}, \Delta T_{\text {friction }}$

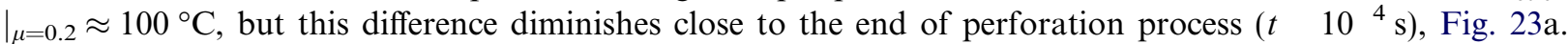
This effect is more important for initial impact velocity $V_{0}$ lower than the ballistic limit as it is shown in Fig. 23b.

The temperature contours at $V_{0} \quad 200 \mathrm{~m} / \mathrm{s}$ (lower value than the ballistic limit) and $V_{0} \quad 600 \mathrm{~m} / \mathrm{s}$ (higher velocity than the ballistic limit) are shown in Figs. 24 and 25. At high initial impact velocity, $V_{0} \quad 600 \mathrm{~m} / \mathrm{s}$, the heat affected zone, HAZ, is approximately the same for $\mu \quad 0$ and $\mu \quad 0.2$, Fig. 24a and b. This can be concluded from the similar plastic work values found for both cases, Fig. 24c. The reduction of the residual velocity caused by $\mu \quad 0.2$ and $\mu \quad 0$ is approximately $\Delta V \quad 10 \mathrm{~m} / \mathrm{s}$.

As shown in Fig. 25, the heat affected zone varies with value of the friction coefficient for velocities lower

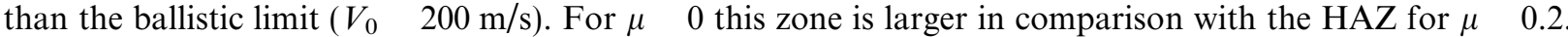
The maximum temperatures are higher in the case of $\mu \quad 0.2$, Fig. 23b. For $\mu \quad 0$ the projectile penetrates

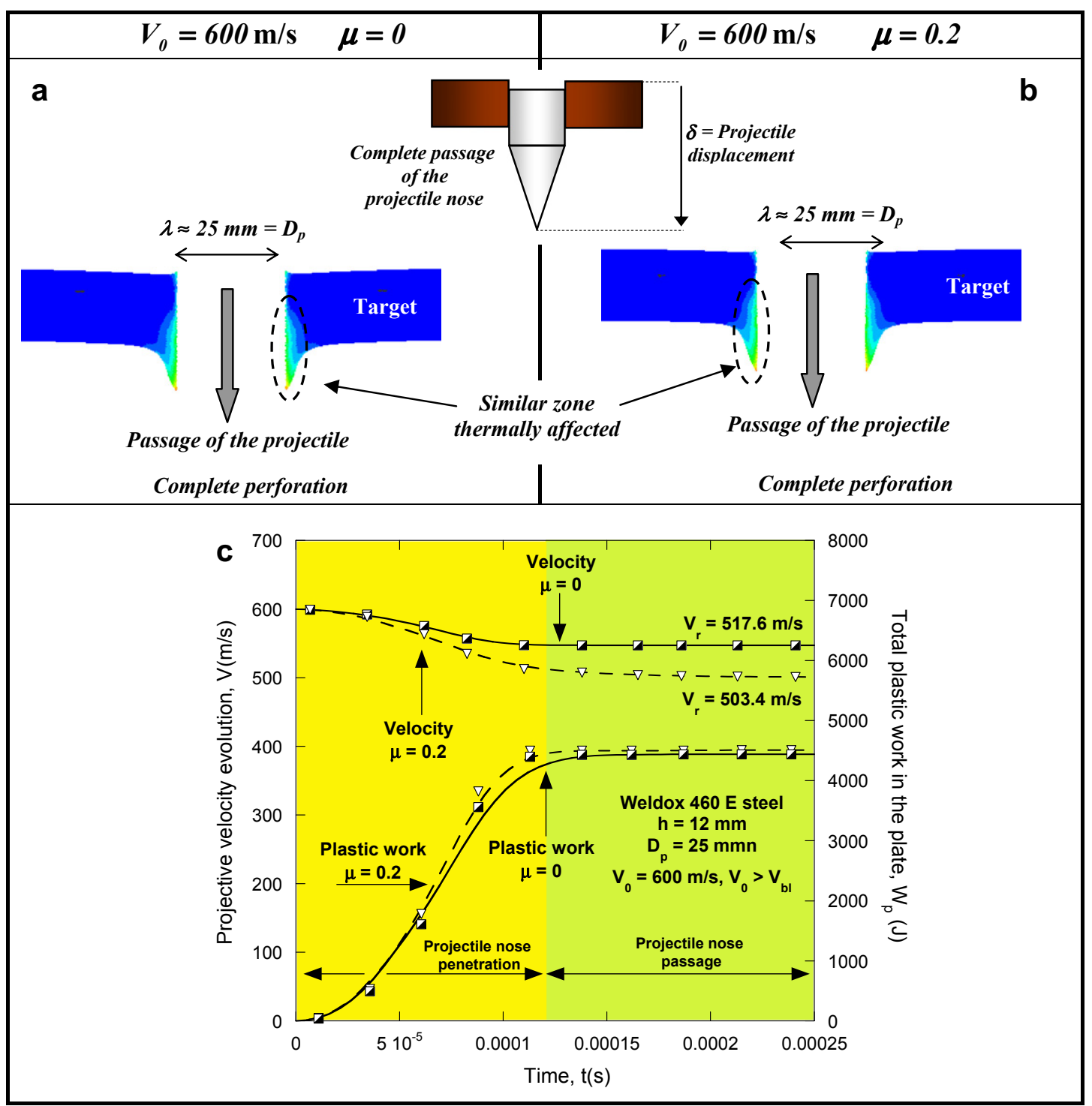

Fig. 24. Temperature increase contours: (a) $\mu=0$, (b) $\mu=0.2$, (c) plastic work and velocity evolution, $D_{\mathrm{p}}=25 \mathrm{~mm}, V_{0}=600 \mathrm{~m} / \mathrm{s}$. 


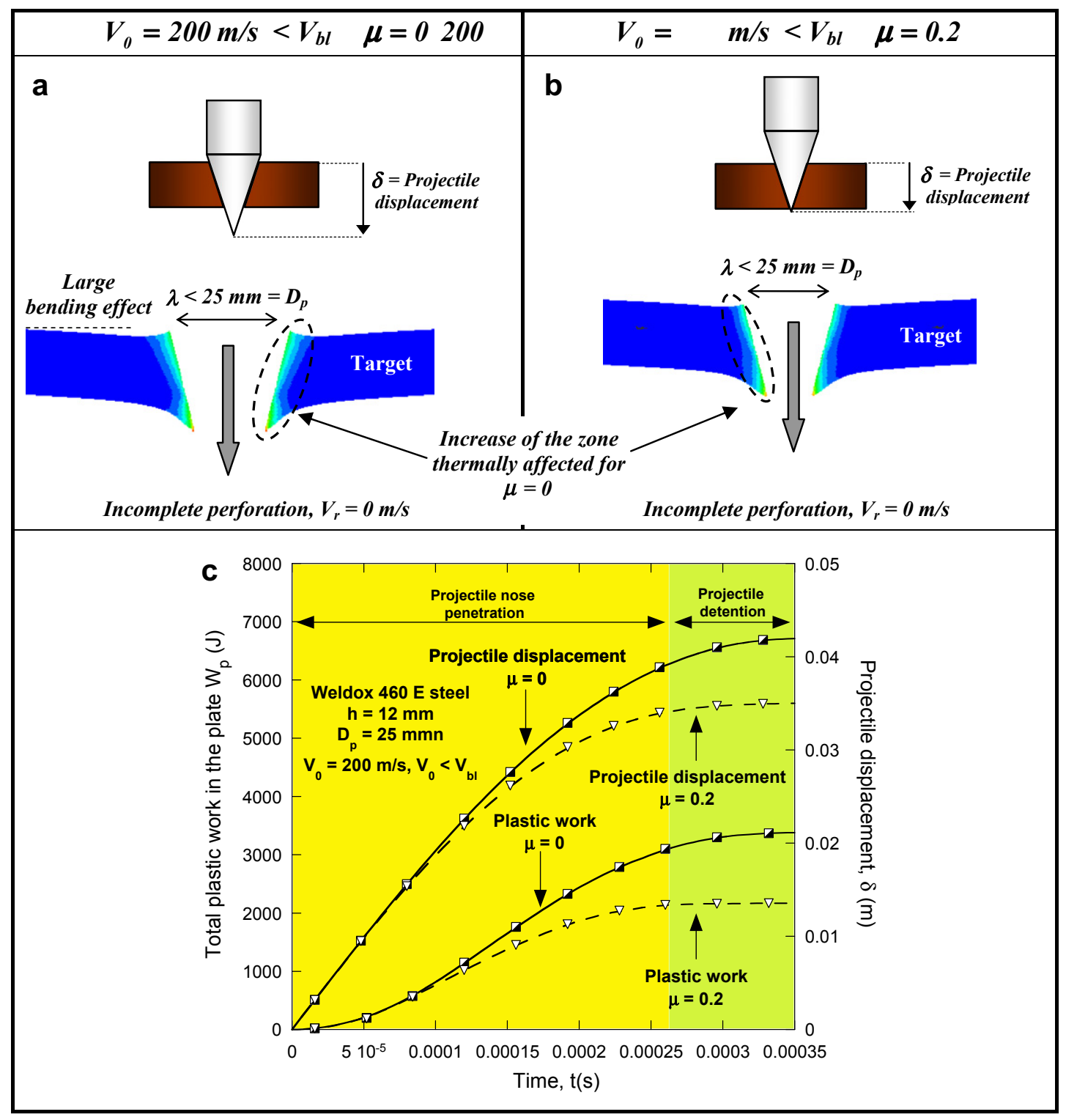

Fig. 25. Temperature contours for the projectile detention time: (a) $\mu=0$, (b) $\mu=0.2$, (c) plastic work and projectile displacement evolution, $D_{\mathrm{p}}=25 \mathrm{~mm}, V_{0}=200 \mathrm{~m} / \mathrm{s}$.

more deeply into the target, inducing greater plastic work, Fig. 25, and causing bending effect, and therefore increasing the HAZ, Fig. 25.

It is therefore observed that friction changes the results only for velocities below the ballistic limit, Fig. 25, since the process is governed by plastic deformation. At higher velocities, due to fast perforation, the time is too short to increase the temperature level.

\section{Conclusions}

In this work, ABAQUS/Explicit has been applied to simulate the normal impact of conical projectiles on Weldox $460 \mathrm{E}$ steel plate. The results obtained from the numerical simulations agree well with the experimental data available in the literature. The adaptive mesh algorithm available in numerical code has been found to be a useful tool in order to avoid the element-distortion problems frequently observed during the penetration 
process. The implementation of this algorithm allows for obtaining a high mesh quality during calculation in all time.

The analysis carried out has permitted to observe that ballistic limit is linear with projectile diameter and therefore proportional to the second power of the nose area, $V_{\mathrm{bl}} \propto D_{\mathrm{p}} \propto A_{\mathrm{c}}^{2}$. Moreover, the velocity lost by the projectile per unit nose area is constant for each initial impact velocity and the evolution of this velocity loss can be approximated by a power law. Thus, it is possible to predict the residual velocity for any other impact velocity and diameter of conical projectile not taken into account in this work.

It is found that the plastic work during penetration diminishes with the initial impact velocity $V_{0}$, due to fast damage localization. The larger the projectile calibre the greater the plastic work is generated in the plate. This is a consequence of the increase of the plastically deformed zone. In addition, the maximum temperature found do not depend on the projectile diameter. This effect demonstrates that for the same nose shape and failure mode, different nose areas do not induce a strong difference in the plastic field distribution. The friction affects the temperature estimations. The maximum values are reached with the highest coefficients of friction.

\section{References}

[1] Honda K, Takamae G, Watanabe T. On the measurement of the resistance of shield plates to penetration by a rifle bullet. In: Tohoku Imperial Univ, first Series, 19, 1930. p. 70325.

[2] Masket A. The measurement of forces resisting armor penetration. J Appl Phys 1949;20:132 40.

[3] Nishiwaki J. Resistance to the penetration of a bullet through an aluminium plate. J Phys Soc Jpn 1951;5:374 8.

[4] Zaid M, Paul B. Mechanics of high speed projectile perforation. J Franklin Inst 1958;35:265 317.

[5] Backman ME, Goldsmith W. The mechanics of penetration of projectiles into targets. Int J Engng Sci 1978;16:1 99.

[6] Corbett GG, Reid SR, Johnson W. Impact loading of plates and shells by free flying projectiles: a review. Int J Impact Engng 1996;18(2):141 230.

[7] Zukas JA, Hohler V, Jameson RL, Mader CL, Nicholas T, Rajendran MA, et al. High velocity impact dynamics. New York: Wiley; 1990.

[8] Zukas JA, Nicholas T, Swift HF. Impact dynamics. Florida: Krieger; 1992.

[9] Borvik T, Langseth M, Hoperstad OS, Malo KA. Perforation of $12 \mathrm{~mm}$ thick steel plates by $20 \mathrm{~mm}$ diameter projectiles with flat, hemispherical and conical noses. Part I: Experimental study. Int J Impact Engng 2002;27(1):19 35.

[10] Borvik T, Langseth M, Hoperstad OS, Malo KA. Perforation of $12 \mathrm{~mm}$ thick steel plates by 20 mm diameter projectiles with flat, hemispherical and conical noses. Part II: Numerical study. Int J Impact Engng 2002;27(1):37 64.

[11] Gupta NK, Iqbal MA, Sekhon GS. Effect of projectile nose shape, impact velocity and target thickness on deformation behavior of aluminum plates. Int J Solids Struct 2007;44(10):3411 39.

[12] Gupta NK, Iqbal MA, Sekhon GS. Experimental and numerical studies on the behaviour of thin aluminium plates subjected to impact by blunt and hemispherical nosed projectiles. Int J Impact Engng 2006;32(12):1921 44.

[13] Arias A, Rodríguez Martínez JA, Rusinek A. Numerical simulations of impact behaviour of thin steel plates subjected to cylindrical, conical and hemispherical non deformable projectiles. Engng Frac Mech 2007. doi:10.1016/j.engfracmech.2007.06.005.

[14] Borvik T, Langseth M, Hoperstad OS, Malo KA. Ballistic penetration of steel plates. Int J Impact Engng 1999;22(9 10):855 86.

[15] Borvik T, Hoperstad OS, Langseth M, Malo KA. Effect of target thickness in blunt projectile penetration of Weldox $460 \mathrm{E}$ steel plates. Int J Impact Engng 2003;28(4):413 64.

[16] Edwards MR, Mathewson A. The ballistic properties of tool steel as a potential improvised armour plate. Int J Impact Engng 1997;19(4):297 309

[17] Atkins AG, Afzal Khan M, Liu JH. Necking and radial cracking around perforations in thin sheets at normal incidence. Int J Impact Engng 1998;21(7):521 39.

[18] Wierzbicki T. Petalling of plates under explosive and impact loading. Int J Impact Engng 1999;22:935 54.

[19] Shen WQ, Rieve RO, Baharun B. A study on the failure of circular plates struck by masses. Part 1: Experimental results. Int J Impact Engng 2002;27:399 412.

[20] Rusinek A, Rodríguez Martínez JA, Zaera R, Klepaczko JR, Sauvelet C, Arias A. Experimental and numerical analysis of failure process of mild steel sheets subjected to perpendicular impact by hemispherical projectiles. Int J Impact Engng, submitted for publication.

[21] Cowper GR, Symonds PS. Strain hardening and strain rate effects in the impact loading of cantilever beams, Brown Univ., Div. of Appl. Mech., Report no. 28, 1952.

[22] Bodner SR, Partom Y. Constitutive equations for elastic viscoplastic strain hardening materials. ASME J Appl Mech 1975;42:385 9.

[23] Steinberg DJ, Cochran SG, Guinan MW. Constitutive model for metals applicable at high strain rates. J Appl Phys 1980;51(3):1498 504.

[24] Nemat Nasser S. On finite deformation elastoplasticity. Int J Solids Struct 1982;18:857 72.

[25] Johnson GR, Cook WH. A constitutive model and data for metals subjected to large strains, high strain rates and high temperatures. In: Proceedings of 7th international symposium on ballistics, 1983. p. 5417. 
[26] Zerilli FJ, Armstrong RW. Dislocation mechanics based constitutive relations for material dynamics calculations. J Appl Phys 1987;61:1816 25.

[27] Khan A. Continuum theory of plasticity. New York: Wiley; 1998 [chapter 8].

[28] Rusinek A, Klepaczko JR. Shear testing of sheet steel at wide range of strain rates and a constitutive relation with strain rate and temperature dependence of the flow stress. Int J Plast 2001;17:87 115.

[29] Liang R, Khan AS. A critical review of experimental results and constitutive models for BCC and FCC metals over a wide rangeof strain rates and temperatures. Int J Plast 1999;15:963 80.

[30] Rusinek A, Zaera R, Klepaczko JR. Constitutive relations in $3 \mathrm{D}$ for a wide range of strain rates and temperatures Application to mild steels. Int J Solids Struct 2007;44:5611 34.

[31] Zaera R, Fernández Sáez J. An implicit consistent algorithm for the integration of thermoviscoplastic constitutive equations in adiabatic conditions and finite deformations. Int J Solids Struct 2006;43(6):1594 612.

[32] Johnson GR, Cook WH. Fracture characteristics of three metals subjected to various strains, strain rates, temperatures and pressures. Engng Fracture Mech 1985;21(1):31 48.

[33] Chen XW, Li QM, Fan SC. Initiation of Adiabatic Shear Failure in a clamped circular plate struck by a blunt projectile. Int J Impact Engng 2005;31(7):877 93.

[34] Teng X, Wierzbicki T, Hiermaier S, Rohr I. Numerical prediction of fracture in the Taylor test. Int J Solids Struct 2005;42(9 10):2929 48.

[35] Rusinek A, Zaera R. Finite element simulation of steel ring fragmentation under radial expansion. Int J Impact Engng 2007;34(4):799 822.

[36] Quinney H, Taylor GI. The emission of latent energy due to previous cold working when a metal is heated. Proc R Soc Lond 1937;163:157 81.

[37] Hancock JW, Mackenzie AC. On the mechanisms of ductile failure in high strength steels subjected to multi axial stress states. J Mech Phys Solids 1976;24:147 69.

[38] Hibbitt HD, Karlsson BI, Sorensen P. Abaqus User's manual, ABAQUS/EXPLICIT 6.5, 2005.

[39] Molinari JF, Gazonas G, Raghupathy R, Rusienk A, Zhou F. The cohesive element approach to dynamic fragmentation: the question of energy convergence. Int J Numer Methods Engng 2007;69:484 503.

[40] Ortiz M, Pandolfi A. Finite deformation irreversible cohesive elements for three dimensional crack propagation analysis. Int $\mathrm{J}$ Numer Methods Engng 1999;44(9):1267 82.

[41] López Puente J, Zaera R, Navarro C. High energy impact on woven laminates. J Phys IV 2003;110(1):639 44

[42] Forquin P, Arias A, Zaera R. Role of porosity in controlling the mechanical and impact behaviours of cement based materials. Int $\mathrm{J}$ Impact Engng 2007. doi:10.1016/i.ijimpeng.2007.01.002.

[43] Zukas JA, Scheffler DR. Practical aspects of numerical simulations of dynamic events: effects of meshing. Int J Impact Engng 2000;24(9):925 45.

[44] Chocron IS, Anderson Jr CE, Grosch DJ, Popelar CH. Impact of the $7.62 \mathrm{~mm}$ APM2 projectile against the edge of a metallic target. Int J Impact Engng 2001;25:423 37.

[45] Chocron IS, Anderson Jr CE, Behner T, Hohler V. Lateral confinement effects in long rod penetration of ceramics at hypervelocity. Int J Impact Engng 2006;33:169 79.

[46] Piekutowski AJ. Debris clouds produced by the hypervelocity impact of nonspherical projectiles. Int J Impact Engng 2001;26:613 24.

[47] Piekutowski AJ. Holes produced in thin aluminium sheets by the hypervelocity impact of aluminium spheres. Int J Impact Engng 1999;23. 711722.

[48] Voyiadjis GZ, Abu Al Rub RK. A finite strain plastic damage model for high velocity impacts using combined viscosity and gradient localization limiters: Part II Numerical aspects and simulations. Int J Damage Mech 2006;15:335 73.

[49] Rusinek A, Gadaj P, Klepaczko JR, Nowacki WK. Simulation of heat exchange during simple shear of sheet steel. J Theo Appl Mech 2002;40:317 37.

[50] Rusinek A, Zaera R, Klepaczko JR, Cheriguenne R. Analysis of inertia and scale effects on dynamic neck formation during tension of sheet steel. Acta Mater 2005;53:5387 400. 